\title{
Macrophage peroxisome proliferator-activated receptor $\gamma$ deficiency delays skin wound healing through impairing apoptotic cell clearance in mice
}

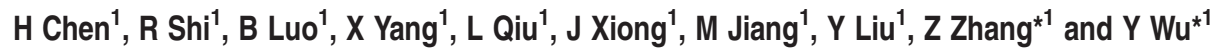

Skin wound macrophages are key regulators of skin repair and their dysfunction causes chronic, non-healing skin wounds. Peroxisome proliferator-activated receptor gamma (PPAR $\gamma$ ) regulates pleiotropic functions of macrophages, but its contribution in skin wound healing is poorly defined. We observed that macrophage PPAR $\gamma$ expression was upregulated during skin wound healing. Furthermore, macrophage PPAR $\gamma$ deficiency (PPAR $\gamma$-knock out (KO)) mice exhibited impaired skin wound healing with reduced collagen deposition, angiogenesis and granulation formation. The tumor necrosis factor alpha (TNF- $\alpha$ ) expression in wounds of PPAR $\gamma$-KO mice was significantly increased and local restoration of TNF- $\alpha$ reversed the healing deficit in PPAR $\gamma$-KO mice. Wound macrophages produced higher levels of TNF- $\alpha$ in PPAR $\gamma$-KO mice compared with control. In vitro, the higher production of TNF- $\alpha$ by PPAR $\gamma-\mathrm{KO}$ macrophages was associated with impaired apoptotic cell clearance. Correspondingly, increased apoptotic cell accumulation was found in skin wound of PPAR $\gamma$-KO mice. Mechanically, peritoneal and skin wound macrophages expressed lower levels of various phagocytosis-related molecules. In addition, PPAR $\gamma$ agonist accelerated wound healing and reduced local TNF- $\alpha$ expression and wound apoptotic cells accumulation in wild type but not PPAR $\gamma$-KO mice. Therefore, PPAR $\gamma$ has a pivotal role in controlling wound macrophage clearance of apoptotic cells to ensure efficient skin wound healing, suggesting a potential new therapeutic target for skin wound healing.

Cell Death and Disease (2015) 6, e1597; doi:10.1038/cddis.2014.544; published online 15 January 2015

The skin is the largest human organ that is essential to protect body against infection and excessive water loss. However, skin is also very easily injured by various attacks. ${ }^{1}$ After injury, the skin needs to restore homeostasis, structure integrity and functional competence. ${ }^{2}$ Skin wound healing is a complicated process orchestrated by interactions of inflammatory cells, resident cells, extracellular matrix components and soluble mediators. The healing process is usually divided into three sequential and overlapping phases: inflammation, proliferation and maturation. ${ }^{3}$ The inflammatory phase includes platelet aggregation, blood coagulation and inflammatory cells recruitment to wound sites. The proliferative phase involves keratinocytes, fibroblasts and endothelial cells migration and proliferation, contributing to reepithelialization, collagen deposition and angiogenesis. And the maturation phase restores tissue structure integrity and functional competence. ${ }^{2}$ If wounds do not progress in the timely and orderly manner, they convert into chronic, non-healing wounds that are a growing world health-care problem related with increasing incidence of diabetes, obesity and aging. ${ }^{4-6}$

Macrophages are the most important immune cells recruited to the wound sites following skin injury, which exhibit pleiotropic functions to orchestrate the healing process throughout the different phases. ${ }^{1,7,8}$ During the earlier inflammation phase, macrophages characterize an proinflammatory phenotype, they release pro-inflammatory mediators such as tumor necrosis factor alpha (TNF- $a$ ), nitric oxide and IL-6, and produce protease and reactive oxygen species to combat contaminating organisms. In pathogen spread wounds, macrophages phagocytose these pathogens and present antigen to $\mathrm{T}$ cells. Macrophages also phagocytose wound debris and apoptotic cells. ${ }^{9}$ Phagocytosis of apoptotic cells predominately switches pro-inflammatory macrophages to anti-inflammatory/wound-healing macrophages to resolve wound inflammation and initiate the healing process. ${ }^{10,11}$ During the later healing phase, macrophages characterize anti-inflammatory/wound-healing phenotype, they produce many cytokines, chemokines and growth factors to crosstalk with keratinocytes, fibroblasts and endothelial cells, contributing to reepithelialization, collagen deposition, angiogenesis, granulation tissue formation and wound repair. $^{12}$ In wound healing, non-functional or dysfunctional macrophages are related with chronic, non-healing wounds.,13-15 Therefore, sustaining macrophage normal functions is critical for successful wound healing. However, the underlying factors regulate macrophage functions during wound healing are not fully known.

Peroxisome proliferator-activated receptors (PPARs) are ligand-activated transcription factors belonging to the nuclear receptor superfamily, which includes three isotypes, PPARa, PPAR $\beta / \delta$ and PPAR $\gamma$. In skin wound healing, PPAR $a$ participates in the control of the early inflammation phase of

\footnotetext{
${ }^{1}$ Department of Basic Medicine, Institute of Immunology, Third Military Medical University of PLA, Chongqing, China

*Corresponding author: Z Zhang or Y Wu, Department of Basic Medicine, Institute of Immunology, Third Military Medical University of PLA, Gaotanyan Street 30, 400038, Chongqing, China. Tel: +86 23 68772229; Fax: +86 23 68752779; E-mail: zhangzhiren@yahoo.com or yuzhangwu@yahoo.com

Abbreviations: ATs, apoptotic thymocytes; KO, knock out; LPS, lipopolysaccharide; PPAR $\gamma$, peroxisome proliferator-activated receptor gamma; RSG, rosiglitazone; TNF- $\alpha$, tumor necrosis factor alpha; WT, wild type

Received 30.5.14; revised 18.10.14; accepted 05.11.14; Edited by D Aberdam
} 
the healing, ${ }^{16}$ PPAR $\beta$ regulates keratinocytes proliferation, adhesion and migration; ${ }^{16-18}$ and PPAR $\delta$ promotes fibroblast proliferation. ${ }^{19}$ However, the role of PPAR $y$ in wound healing is not elucidated. It is well known that PPARy is a key factor transcriptionally coordinates macrophage functions. ${ }^{20}$ Macrophage PPAR $y$ signaling is essential for the efficient clearance of apoptotic cells ${ }^{21,22}$ and the switching from pro-inflammatory macrophages to anti-inflammatory macrophages, ${ }^{23,24}$ which are important for resolving inflammation and maintaining homeostasis. In this study, we generated mice with macrophage PPAR $y$ deficiency to investigate the role of macrophage PPARy in the healing of skin wounds.

\section{Results}

PPARy is upexpressed in wounded skin and wound macrophage. We first investigated the temporal and spatial expression of PPARy during skin wound healing in wild-type (WT) mice (Figures 1a and b). Low levels of PPARy (mRNA and protein) were observed in unwounded control skin (day $0)$. However, a significant increase of mRNA and protein levels of PPARy was observed after wounding (days 3, 5, 7, 10 and 12). Immunohistochemical staining showed that PPARy protein was significantly enhanced in both subcutaneous (s.c.) and dermis of wounded skin (Figure 1c) compared with normal skin (Supplementary Figure 1). In addition, flow cytometric analysis showed that wound macrophage upregulated PPARy expression during the healing process (Figure 1d). These results suggest a potential involvement of macrophage PPARy in the regulation of skin wound healing.

Characterization of macrophage PPAR $\boldsymbol{y}$ deficiency mice. To investigate the role of macrophage PPARy in wound healing, conditional knock out (KO) mice lacking macrophage expression of PPARy were generated by crossing mice bearing the lox-P-targeted PPARY $\left(P P A R \gamma^{f / f}\right)$ allele with mice bearing the lysozyme-M Cre (LysMCre) recombinase transgene. We refer to $P P A R \gamma^{t / f} L_{y s M C r e}{ }^{-}$mice as control (PPARY-WT), and their PPAR ${ }^{f / f} L y s M C r e^{+}$littermates as $\mathrm{KO}$ animals (PPARY-KO).

Genotyping of the tail DNA confirmed the presence of Cre transgene in PPARY ${ }^{f /+} L_{\text {LSMCre }}^{+}$and PPAR $\gamma^{f / f}$ LysMCre $^{+}$mice and its absence in WT mice (Figure 2a). Peritoneal macrophages from PPARY-KO mice showed significant lower levels of PPAR $y$ mRNA and protein compared with their control macrophages (Figures $2 \mathrm{~b}$ and $\mathrm{c}$ ), and wound macrophages from PPARY-KO mice had lower PPARY expression (Figure 2d). In addition, both PPARY-WT and PPARY-KO wound neutrophils showed no evidence for PPARy staining, and PPARy expression in splenic T cells, B cells and dendritic cells were not significantly different between $P P A R Y-W T$ and $P P A R Y$-KO mice (Supplementary Figure 2). These results indicated an efficient and specific macrophage PPARy ablation.

In addition, the temporal profile of PPAR $\mathrm{mRNA}$ and protein levels in skin wounds were compared between $P P A R y-\mathrm{KO}$ and $P P A R y$-WT mice. Significant lower levels of PPARy (mRNA and protein) were observed in $P P A R \gamma-\mathrm{KO}$ mice compared with
WT mice after wounding (days 3, 5, 7 and 10; Figure 2e), indicating an important contribution of macrophage PPARy to the increased PPARy expression observed during skin wound healing.

Delayed wound healing in mice with macrophage PPAR $\boldsymbol{y}$ deficiency. Thereafter, full-thickness circular wounds were produced on PPARY-WT and PPARY-KO mice. The wound sizes were monitored daily. In addition, we found that wound closure in PPARY-KO mice was significantly delayed from 3 to 12 after wounding compared with PPARY-WT mice (Figure 3a). Next, we detected granulation formation, collagen deposition and angiogenesis during wound healing, focusing on days 5 and 7 , when mainly granulation tissue formation, collagen deposition and angiogenesis occur.

Hematoxylin and eosin (H\&E) staining of 5-day-old wounds showed that areas of granulation tissue was markedly reduced at the wound sites in PPARY-KO mice compared with PPARYWT mice (Figure $3 \mathrm{~b}$ and Supplementary Figure $3 \mathrm{a}$ ).

To examine collagen deposition, 5- and 7-day-old wounds were stained with Masson trichrome. At the wound edge, characterized by the acanthotic keratinocyte layer, new and old collagen can be observed. The old collagen away from the wound margin in both strains of mice stains dark blue (Supplementary Figure 3b, closed arrow). The newly formed collagen near the wound margin is below the acanthotic keratinocyte layer (Supplementary Figure 3b, open arrow). Both 5- and 7-day-old wounds in PPARY-KO mice contained lower areas of new collagen compared with the PPARY-WT wounds (Supplementary Figure 3b). To further quantitatively assess collagen deposition, collagen type 1 mRNA expression was analyzed by real-time polymerase chain reaction (RT-PCR) and a significantly higher level was detected on days 3,5 and 7 wounds of PPARY-WT mice compared with that of PPARY-KO mice (Figure $3 c$ ).

To examine the rate of angiogenesis, immunohistochemistry analysis of CD31 was carried out. The wounds of PPARYWT had higher density of new blood vessels in the granulation tissue compared with wounds of PPARY-KO mice (Figure 3d and Supplementary Figure $3 c$ ). Consistently, the mRNA level of vascular endothelial growth factor (VEGF) in wounds was significantly decreased in PPARY-KO mice compared with PPARy-WT mice (Figure 3d).

Overall, wound healing is severely impaired both macroscopically and microscopically in PPARY-KO mice.

Wounds of PPARY-KO mice exhibit normal numbers of neutrophils and macrophages. It is well known that inflammatory cells have a vital role in normal skin wound healing and impairing inflammatory cell recruitment to wound sites severely affects wound healing. ${ }^{25-31}$ So we next measured the leukocyte accumulation to skin wound sites between PPARY-WT and PPARY-KO mice. Immunohistochemistry staining of day 3 wounds with antibodies specific to neutrophils (Ly-6G) or macrophages (F4/80) were shown (Supplementary Figure 4). The numbers of neutrophils and macrophages were counted within the granulation tissues of wounds at indicated time points and no significant difference between both mice strains was seen (Figure 4a). Furthermore, flow cytometry was used to measure the numbers of 


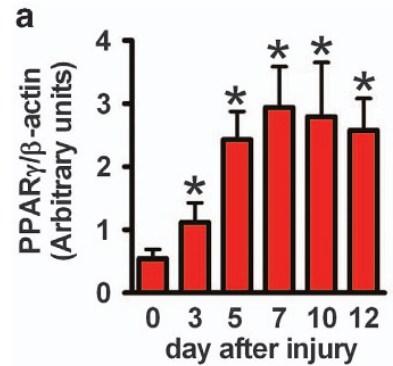

b

C
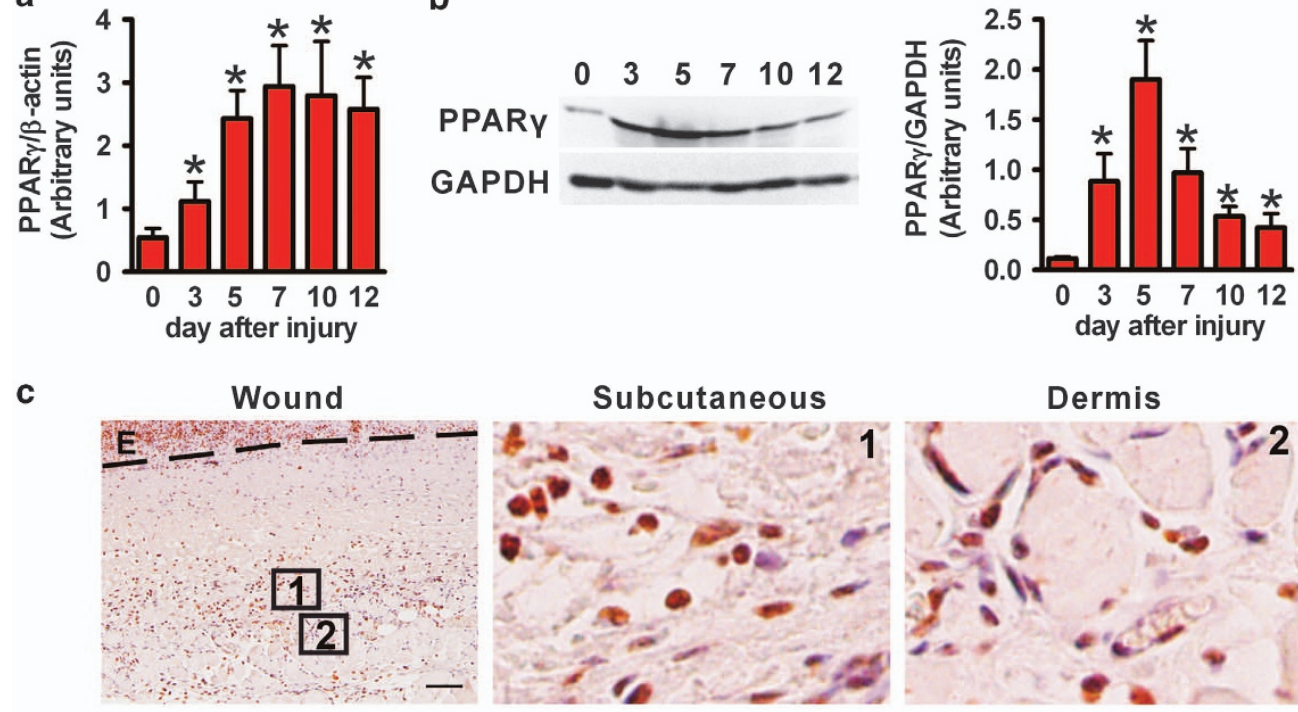

d

Day 3

Day 5
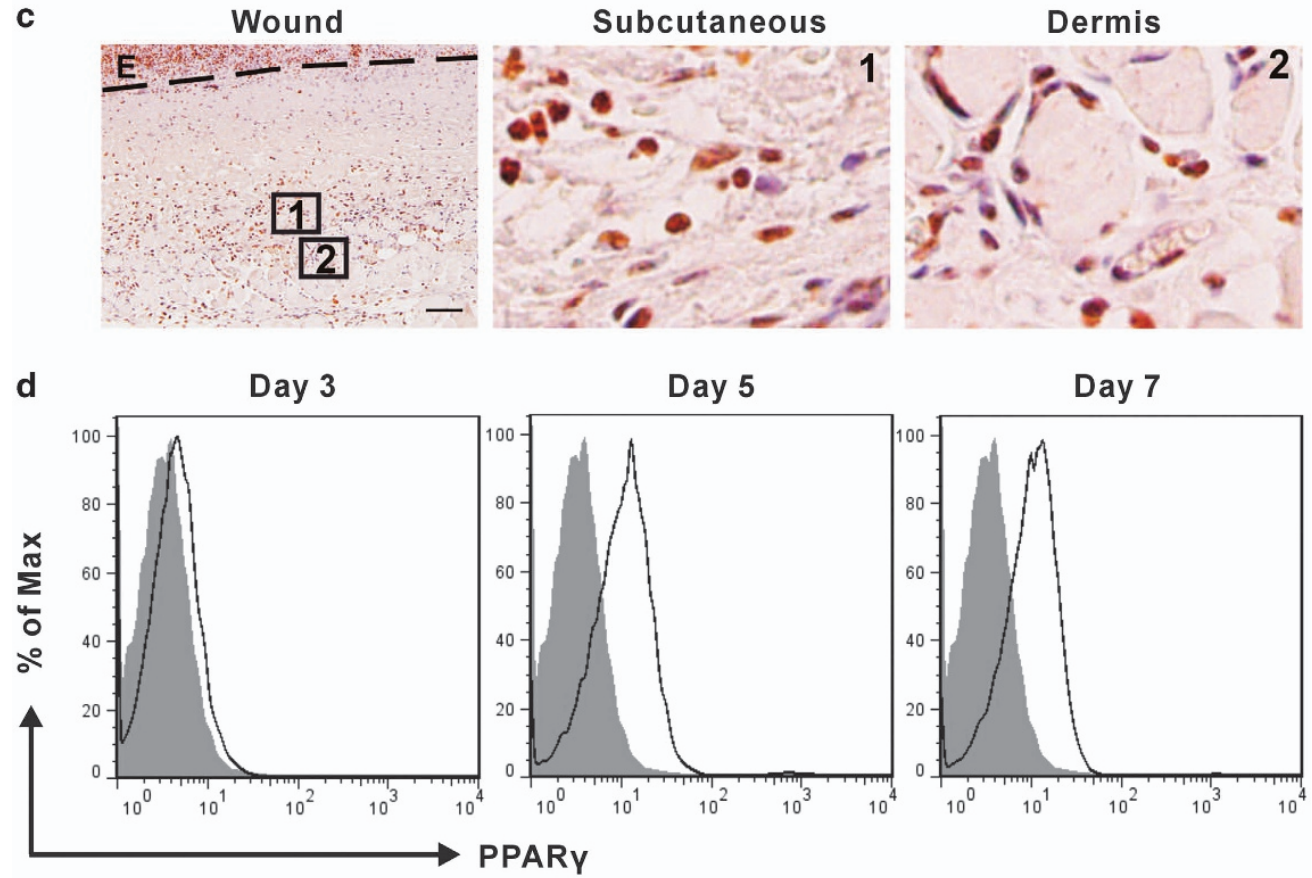

Day 7
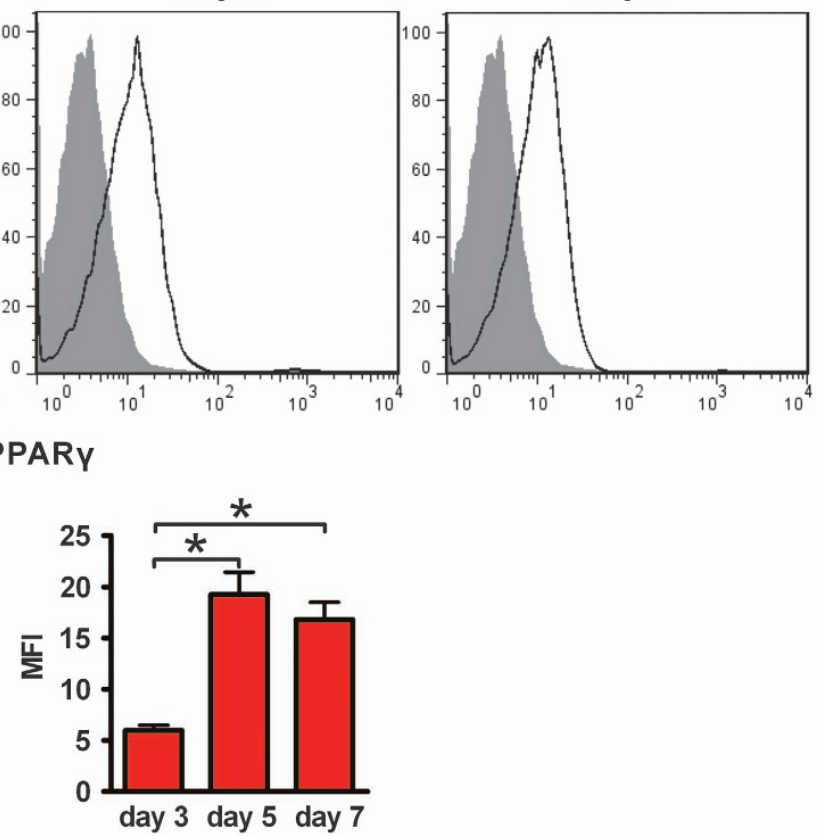

Figure 1 PPAR $\gamma$ expression during wound healing of WT mice. (a) mRNA and (b) protein levels of PPAR $\gamma$ in wounds. mRNA expression (a) is normalized to $\beta$-actin and the protein expression (b) is normalized to GAPDH. ${ }^{*} P<0.05$, wounded skin versus normal skin. (c) Immunohistochemical staining of PPAR $\gamma$ expression in wounded skin on day 5 after wounding. Boxed areas of s.c. (number 1) and dermis (number 2) tissue in the left panel are enlarged in the middle and right panel. Black hatched line lines eschar. E, eschar. Scale bar $=50 \mu \mathrm{m}$. (d) Flow cytometric analysis of PPAR $\gamma$ expression in wound macrophages on days 3,5 and $7 . \mathrm{CD} 11 \mathrm{~b}^{+} \mathrm{F} 4 / 80^{+}$was used to gate macrophages. Isotype control, gray histogram; PPAR $\gamma$, unshaded histogram. Mean fluorescence intensity (MFI) is shown. ${ }^{*} P<0.05$. Data are expressed as mean \pm S.D. and images are representative, $n=3$ for each time point

neutrophils and macrophages in skin wound on days 1, 2 and 3 after polyvinyl alcohol (PVA) sponge insertion, and no significant differences were observed between both mice strains as well (Figure 4b). These results indicated that the recruitment of neutrophils and macrophages to skin wound in $P P A R Y-W T$ and PPARY-KO mice are similar.

Local restoration of TNF-a rescues impaired wound healing in PPARY-KO mice. Other than inflammatory cells, cytokines, growth factors and chemokines regulate the wound healing as well. Accumulated evidences indicate that enhancing local TNF- $a$ expression delays wound healing, reduces collagen deposition and suppresses angiogenesis. $^{32-37}$ So we next measured TNF- $a$ levels in wound tissues of PPARY-KO versus PPARY-WT mice by RT-PCR, western blotting (WB) and ELISA. Neither mRNA levels nor protein expression of TNF- $a$ have significant difference between PPARY-KO and PPARY-WT mice in day 0 wounds 
a

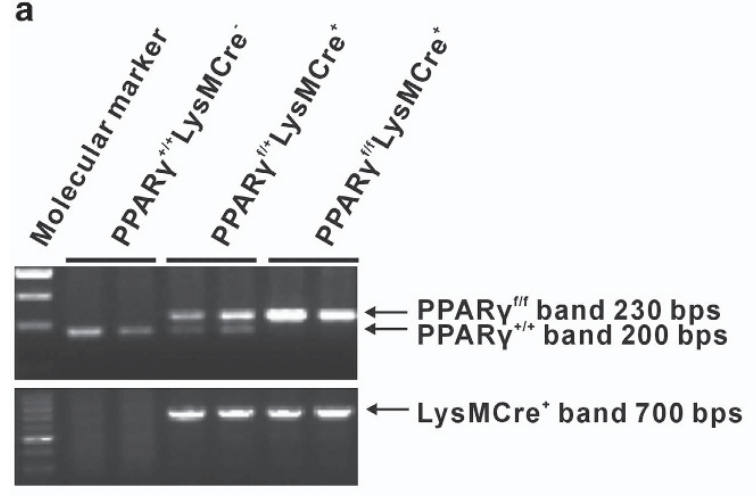

b
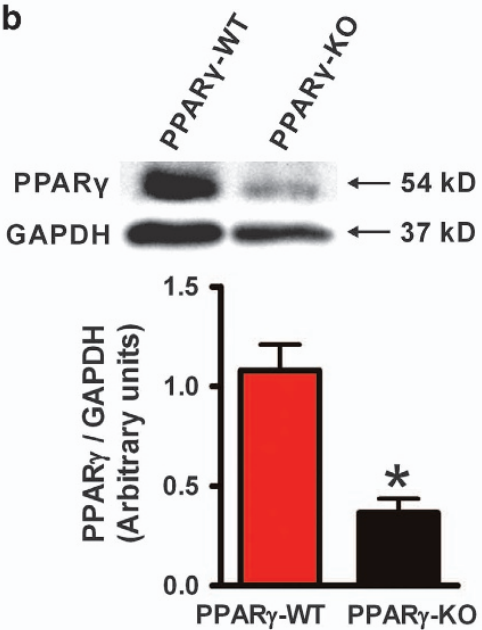

c

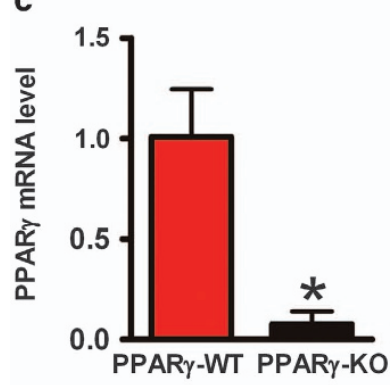

d

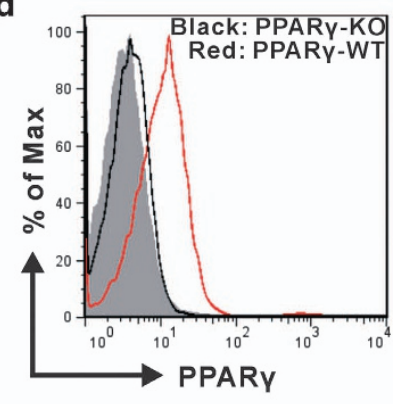

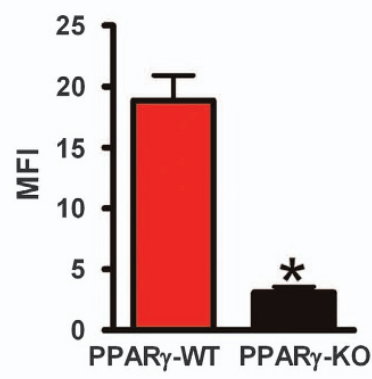

e WT

PPARY-KO
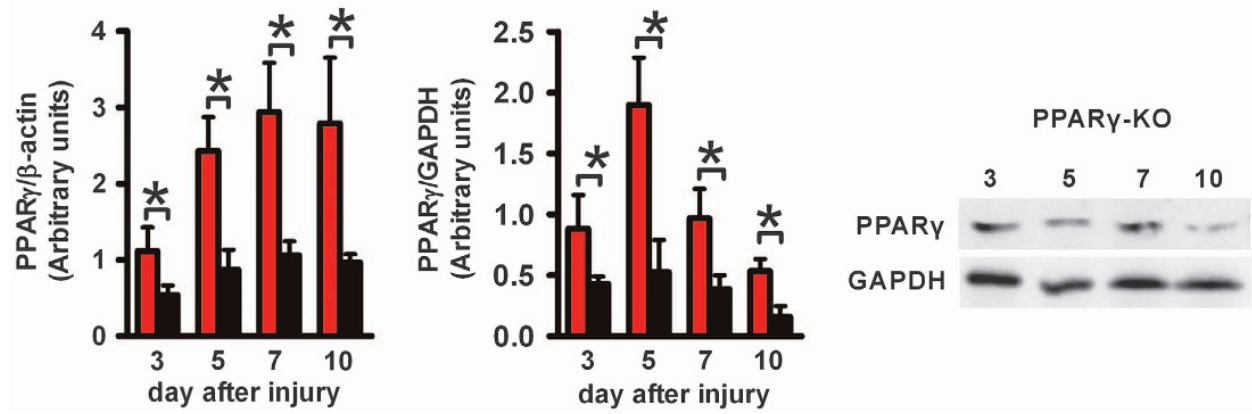

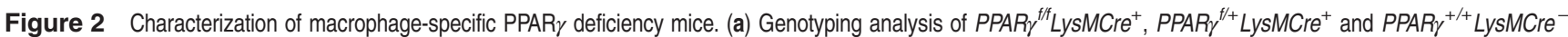
(PPARy-WT) mice. (b) WB and (c) RT-PCR analysis of PPAR $y$ expression in isolated peritoneal PPARy-WT and PPARy-KO macrophages. Protein expression is normalized by GAPDH. mRNA expression is normalized by $\beta$-actin and represented as the fold change in PPARy-KO macrophages compared with PPAR $\gamma$-WT macrophages. (d) Flow cytometric analysis of PPAR $\gamma$ expression in isolated PPAR $\gamma$-WT and PPAR $\gamma$-KO wound macrophages. $\mathrm{CD} 11 \mathrm{~b}^{+} \mathrm{F} 4 / 80^{+}$was used to gate macrophages. Isotype control, gray histogram; PPAR $\gamma$, unshaded histogram (red histogram: PPAR $\gamma$-WT; black histogram: PPAR $\gamma$-KO). Mean fluorescence intensity (MFI) is shown. For (b-d), ${ }^{*} P<0.05, P P A R \gamma-K O$ versus PPAR $\gamma$-WT. (e) mRNA and protein levels of PPAR $\gamma$ in wounds of WTand PPAR $\gamma$-KO mice. mRNA expression is normalized by $\beta$-actin and protein expression is normalized by GAPDH. ${ }^{*} P<0.05$. Data are expressed as mean \pm S.D. and images are representative, $n=3$ for each time point and group

(Figures $5 \mathrm{a}$ and b). After injury, the expression levels of TNF- $a$ were increased in 5-day-old wounds of both strains mice. However, a significant higher expression of TNF- $a$ both at mRNA and protein level were observed in 5-day-old wounds of PPARY-KO mice compared with PPARY-WT mice (Figures $5 \mathrm{a}$ and $\mathrm{b}$ ).

These results suggested a significant increase of TNF- $a$ following macrophage PPARy deficiency, which may account for the delayed wound healing. So we next s.c. injected rat anti-mouse TNF- $a$ (aTNF- $a$ ) around the wound. ${ }^{35,36}$ In addition, mock injections of isotype control antibody were taken as controls. In PPARY-KO mice, local injection of aTNF- $a$ improved skin wound healing, granulation tissue formation, collagen deposition and angiogenesis to the level similar to that in WT mice without any treatment, indicating a full rescue (Figures $5 \mathrm{c}-\mathrm{f}$ and Supplementary Figures $5 \mathrm{a}$ and $\mathrm{c}$ ). These data suggest that the increased local TNF- $a$ expression is causal to the delayed wound healing in PPARY-KO mice. 

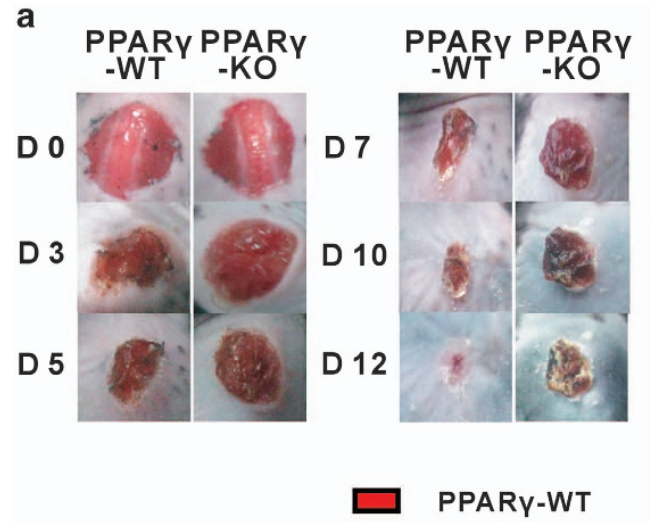

b

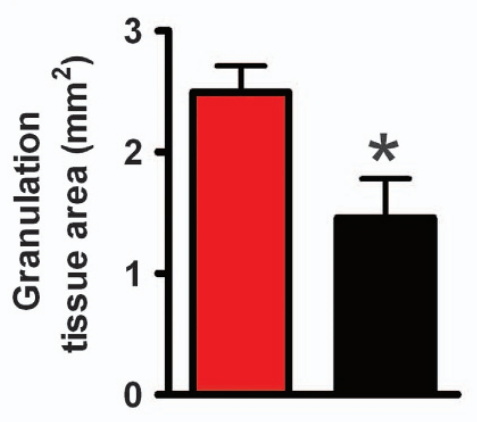

d

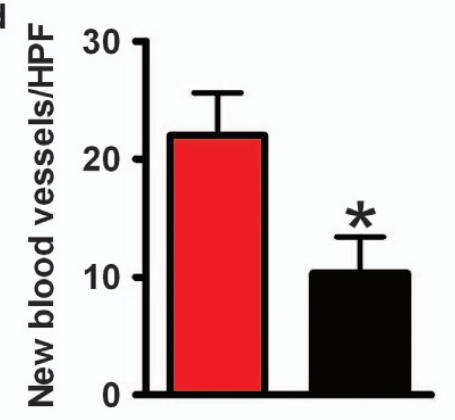

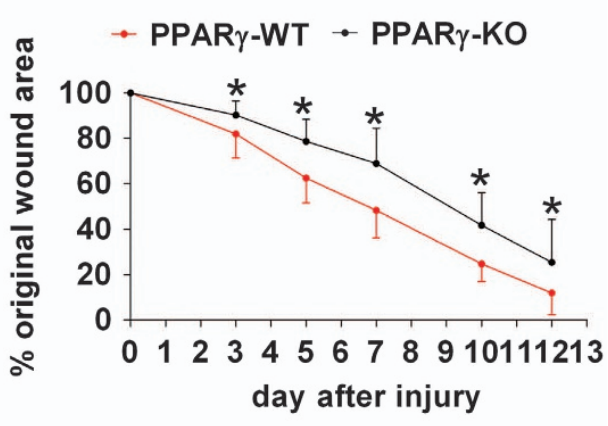

\section{PPARY-KO}

c
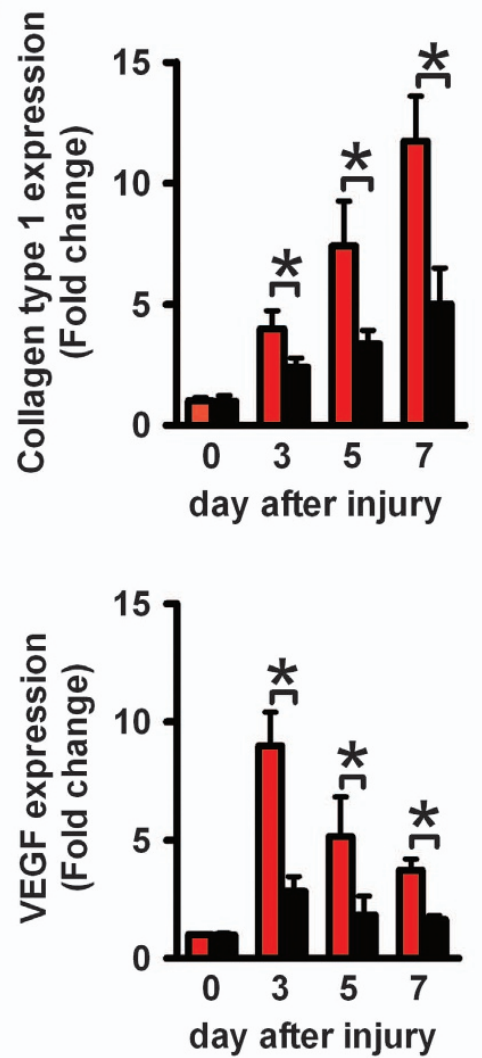

Figure 3 Delayed wound healing in PPARy-KO mice. (a) Representative wounds, and statistical analysis of wound areas expressed as percentage of the initial (day 0 ) wound size. $n=12$, for each time point and group. (b) The areas of granulation tissue in 5-day-old wounds. (c) mRNA expression of collagen type 1 in wounds. (d) Quantification of new blood vessels in the granulation tissue of 5-day-old wounds in 3-5 high-power fields (HPFs) per mice, and mRNA expression of VEGF in wounds. For (b-d), $n=3$ for each time point and group. All data are expressed as mean \pm S.D. ${ }^{*} P<0.05$, PPAR $y$-WT versus PPAR $\gamma$-KO mice

Impaired apoptotic cell clearance by macrophages contributes to increased wound TNF-a expression in PPAR $\boldsymbol{Y}$-KO mice. As macrophages represent a major source of the cytokines in wounds, $^{38}$ we speculated that PPARY-KO macrophages may release more TNF- $a$ compared with $P P A R Y$-WT macrophages during wound healing. Therefore, we detected TNF-a expression in isolated wound macrophages and found that $P P A R Y-K O$ wound macrophages expressed more TNF- $a$ than their PPARY-WT counterparts (Figure 6a).

To explore how PPARy regulates wound macrophage TNF- $a$ production, we next analyzed TNF- $a$ mRNA levels in peritoneal macrophages of both mice strains stimulated with or without lipopolysaccharide (LPS). Unstimulated PPARY-WT and PPARY-KO macrophages expressed similar low-level of TNF- $a$ (Figure 6b). Although LPS greatly upregulated TNF- $a$ expression in PPARY-WT and PPARY-KO macrophages, no significant difference was observed between these two stains of macrophages (Figure $6 \mathrm{~b}$ ). In addition, similar results were further confirmed at protein level (Figure 6c), indicating that PPAR $y$ has no direct effect on TNF- $a$ production in macrophages after LPS stimulation. However, in the presence of apoptotic thymocytes (ATs), PPARY-WT macrophages significantly reduced LPS-induced TNF- $a$ production (at both 

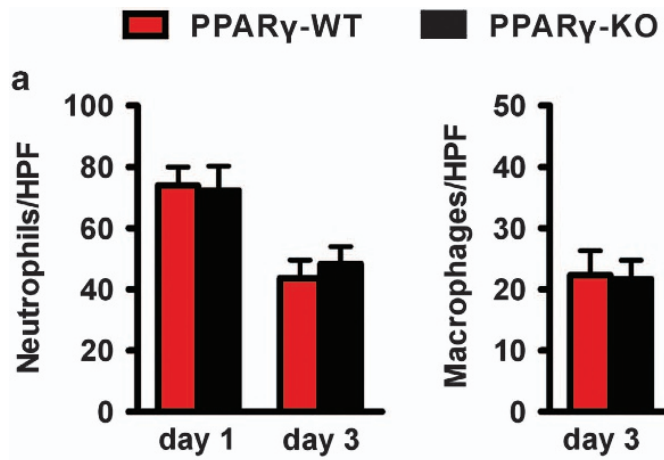

b

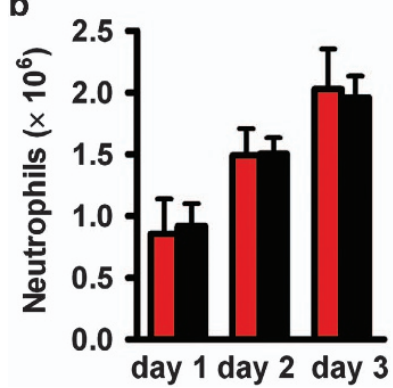

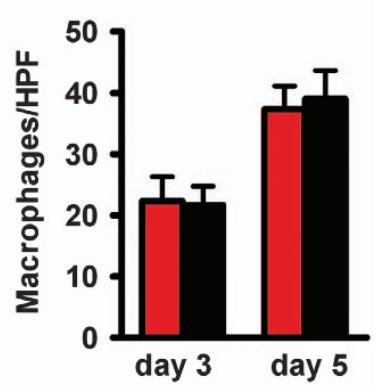

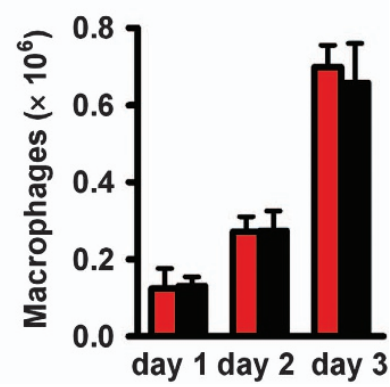

Figure 4 There is no difference in inflammatory cell recruitment to the wounds of PPARy-WT and PPARy-KO mice. (a) Quantification of $\mathrm{Ly}^{-6 \mathrm{G}^{+}}$neutrophils within granulation tissues of 1 - and 3 -day-old wounds, and $\mathrm{F} / 80^{+}$macrophages within granulation tissues in 3- and 5-day-old wounds in 3-5 high-power fields (HPFs) per mice. (b) Wound cells derived from PVA sponges after days 1,2 and 3 inserting. The numbers of neutrophils and macrophages were shown. SSChigh $L y-6 \mathrm{G}^{+}$was used to gate neutrophils and $\mathrm{FSC}^{\text {high }} \mathrm{F} 4 / 8 \mathrm{O}^{+}$was used to gate macrophages. Data are expressed as mean \pm S.D., $n=3$ for each time point and group

mRNA and protein level), but PPARY-KO macrophages were not (Figures $6 \mathrm{~b}$ and $\mathrm{c}$ ), suggesting that the relative increased TNF- $a$ expression in PPARY-KO macrophages was because of the failure of ATs phagocytosis. For further demonstration, the actin-filament polymerization-blocking agent cytochalasin $B$ was used to inhibit macrophage phagocytic activity and the added ATs were found to have no effect on TNF- $a$ expression in both macrophages strains (Figures $6 b$ and $c$ ). Furthermore, the direct measurement of ATs engulfment by flow cytometry clearly showed that the phagocytic activity of PPARy-KO macrophage was severely impaired (Figure $6 \mathrm{~d}$ ). These in vitro results suggested that $P P A R y-K O$ macrophages produced excessive TNF- $a$ because of an impaired phagocytic activity.

For in vivo study, TUNEL staining was applied to detect apoptotic cell accumulation in skin wound. We observed that the wounds (days 3, 5 and 7) of PPARY-KO mice contained higher number of apoptotic cells compared with that in $P P A R Y$ WT mice (Figure 6e and Supplementary Figure 6a). Furthermore, wound cells of PPARY-KO mice had higher percentage of apoptotic neutrophils compared with PPARY-WT mice (Figure 6f), indicating decreased apoptotic cell engulfment by PPARY-KO macrophages in skin wound.

Shortly, these results indicated that PPARy deficiency impaired macrophage phagocytosis of apoptotic cells, resulting in macrophage producing of excessive TNF- $a$, contributing to increased TNF-a level in wounds.
PPARy regulates the expression of genes involved in the phagocytosis of apoptotic cells by macrophages. To understand the underlying molecular mechanism of the deficit in apoptotic cell clearance observed in our mouse model, we profiled the transcription of a set of genes encoding phagocytosis-associated receptors and opsonins in PPARY-WT and PPARY-KO macrophages. Among them, Cd36 and Mertk are cell surface receptors and required for proper binding and consequent internalization of apoptotic cells. ${ }^{39}$ Mfge8, Gas6, and the C1q subunits C1qa, C1qb and $\mathrm{C} 1 \mathrm{qc}$ are opsonins, which bind to apoptotic cell surface to initiate phagocytosis. ${ }^{40}$

In PPARY-WT and PPARY-KO macrophages, the expression of Cd36, Mertk, Mfge8, C1qb and C1qc was reduced in $P P A R Y$-KO macrophages. However, PPARy deficiency had no effect on the expression of Gas6 and C1qa (Figure 7a). As digestion of apoptotic cells by macrophage leading to accumulation of cellular components, such as cholesterol and fatty acids, which may act as endogenous ligands for PPAR $\gamma,{ }^{41}$ we incubated both strains of macrophage with ATs, the results showed the mRNA levels of Cd36, Mertk, Mfge8, Gas6 and all three C1q subunits were higher in PPARy-WT macrophages compared with the absence of ATs, which was not observed in PPARY-KO macrophages (Figure 7a). Furthermore, activation of PPARy using rosiglitazone (RSG), which is a selective agonist of PPAR $y$, increased the expression of Cd36 and Mertk in PPARY-WT macrophages but not in $P P A R Y-K O$ cells. However, RSG did not significantly increase the expression of Mfge8, Gas6, C1qa, C1qb and C1qc in $P P A R Y$-WT macrophages (Figure $7 \mathrm{~b}$ ). In addition, isolated macrophages from wound of PPARY-KO mice decreased the expression of all the detected phagocytosis-related genes (Figure 7c). These results indicated that PPARy deficiency in macrophages decreased the expression of phagocytosisrelated molecules, which may contribute to the reduced apoptotic cell clearance.

Therapeutic targeting PPARy accelerates skin wound healing in normal mice. Owing to PPARy upexpression in wounded skin and delayed wound healing in mice with macrophage PPARy deficiency, we speculated that PPAR $y$ may have a vital role in regulating skin wound healing. RSG treatment of skin wound in WT mice resulted in accelerated wound healing, reduced apoptotic cell aggregation and lower local TNF- $a$ expression compared with a control treatment (Figures 8a-c and Supplementary Figure 6b). However, RSG has no therapeutic effects in PPARY-KO mice (Figures $8 \mathrm{a}-\mathrm{c}$ and Supplementary Figure 6b).

\section{Discussion}

PPARy has a key role in regulating macrophage phagocytic activity during skin wound healing. In this study, PPARy was upregulated in wounded skin and wound macrophages indicating that macrophage PPAR $y$ may regulate the healing process. Thus, we generated macrophage PPAR $y$ deficiency mice. These mice exhibited efficient and specific macrophages PPARy ablation, not targeting other immune cells, such as neutrophils, dendritic cells, T cells and B cells, which may influence the skin wound inflammation. Furthermore, the 
a

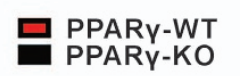

b

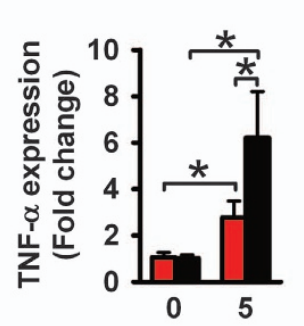

D 0

D 0

D

D 5

TNF- $\alpha$

GAPDH

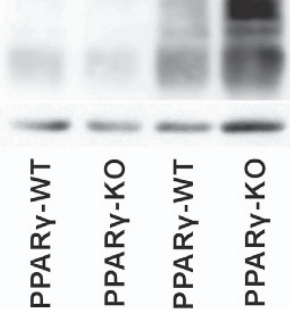

口 PPARY-WT DPARY-KO

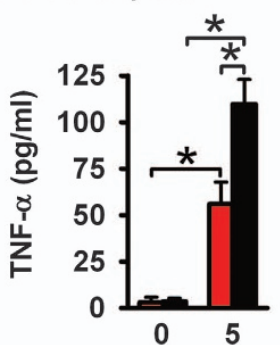

C
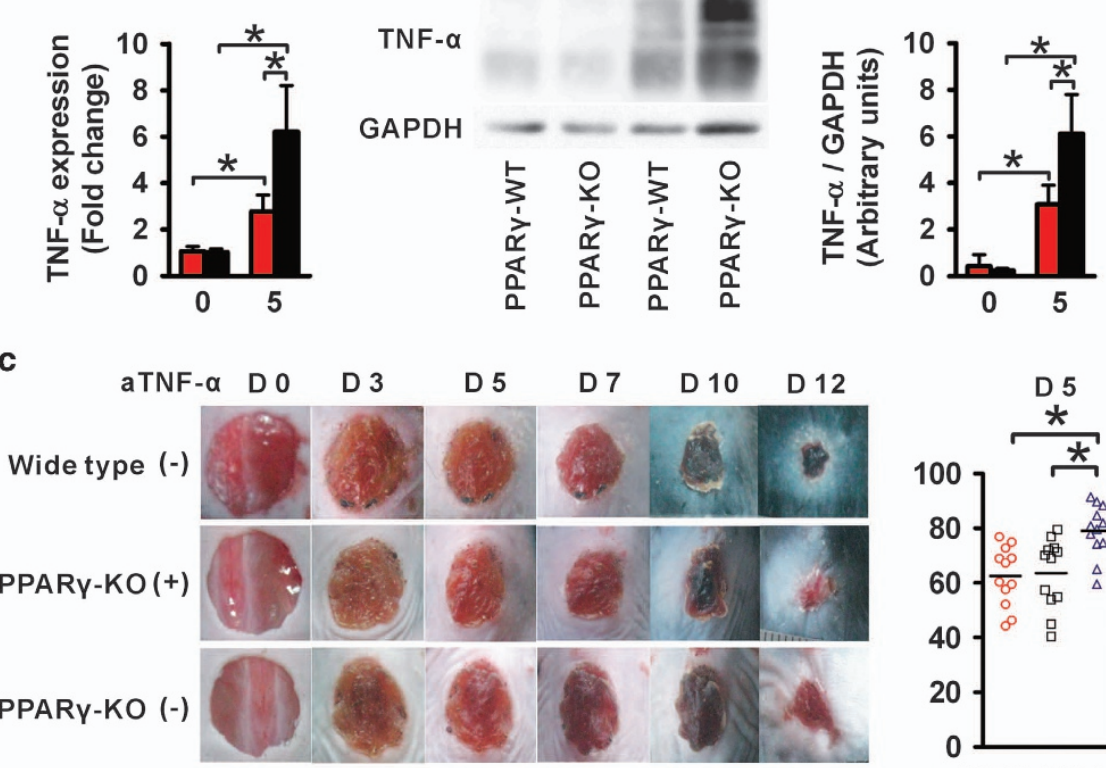

D 10

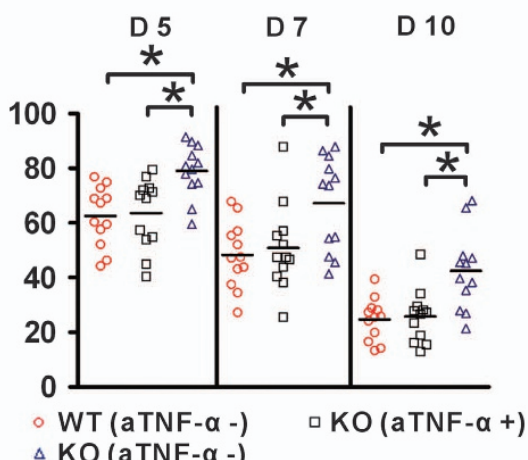

Wide type (aTNF- $\alpha-$ )

PPARY-KO (aTNF- $\alpha+)$

PPARY-KO (aTNF- $\alpha-)$

d

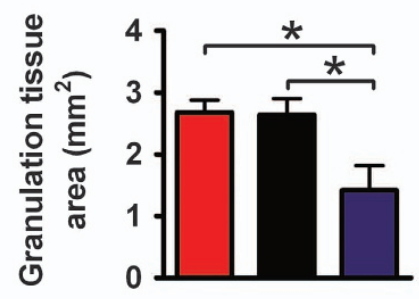

f

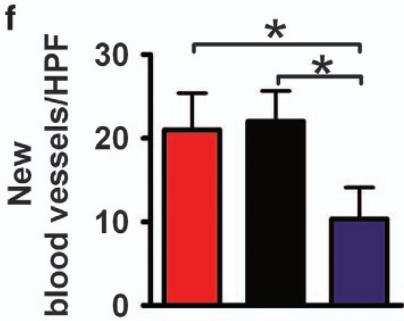

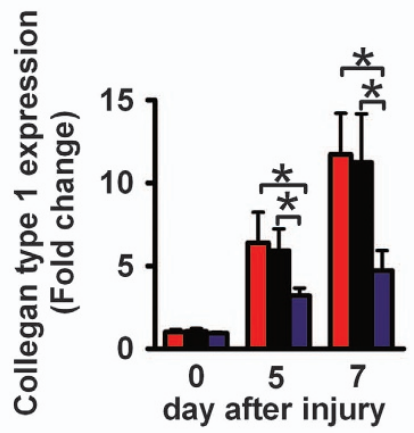

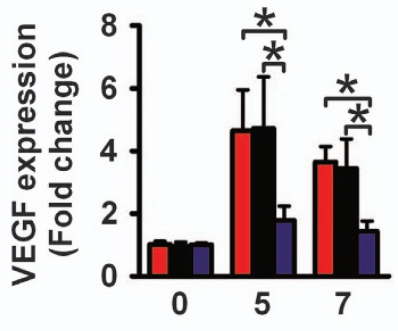

day after injury

Figure 5 Enhanced expression of TNF- $\alpha$ in wounds is causal for the wound healing defect of PPARy-KO mice. (a) mRNA and (b) protein expression of TNF- $\alpha$ in normal skin and 5-day-old wounds. (c) Representative wounds, and statistical analysis of wound areas expressed as percentage of the initial (day 0 ) wound size. $n=12$, for each time point and group. (d) The areas of granulation tissue in 5-day-old wounds. (e) mRNA expression of collagen type 1 in wounds. (f) Quantification of new blood vessels in the granulation tissue of 5-day-old wounds in 3-5 high-power fields (HPFs) per mice, and mRNA expression of VEGF in wounds. For (a), (b), (d), (e) and (f), $n=3$ for each time point and group. All data are expressed as mean \pm S.D. and images are representative. ${ }^{*} P<0.05$

expression of PPARy in skin was not upregulated during wound healing in PPARY-KO mice, suggesting an ablation of PPARy in wound macrophage. PPARY-KO mice reduced granulation tissue formation, collagen deposition and angiogenesis, and delayed wound closure. In PPARY-KO mice, the TNF- $a$ expression was increased in skin wound and local inhibition of TNF- $a$ rescued healing deficit in PPARY-KO mice, indicating that the excessive TNF- $a$ contributed to the 

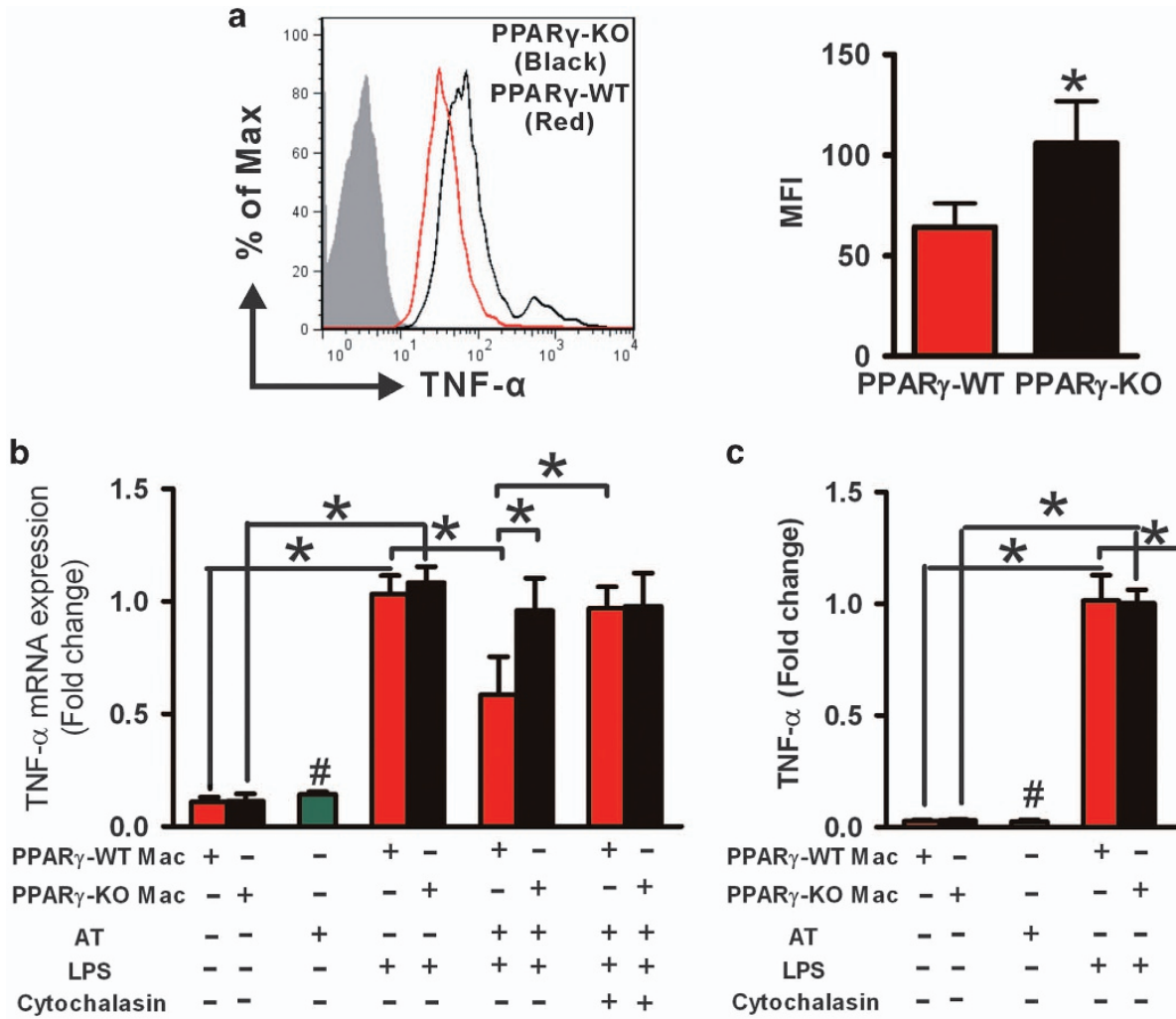

C

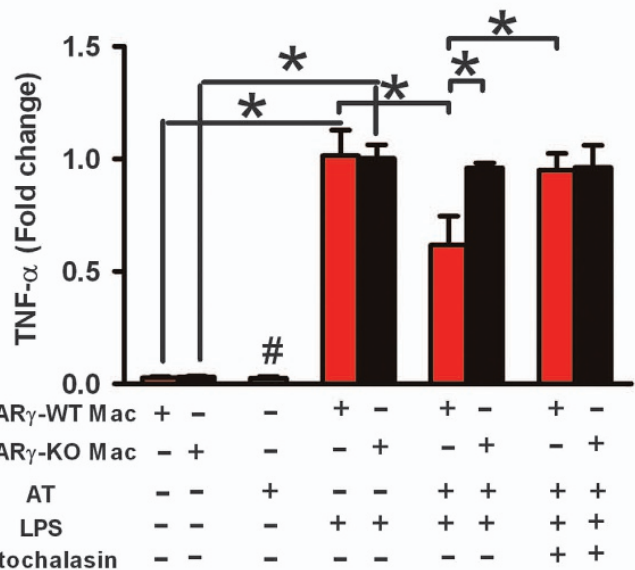

d
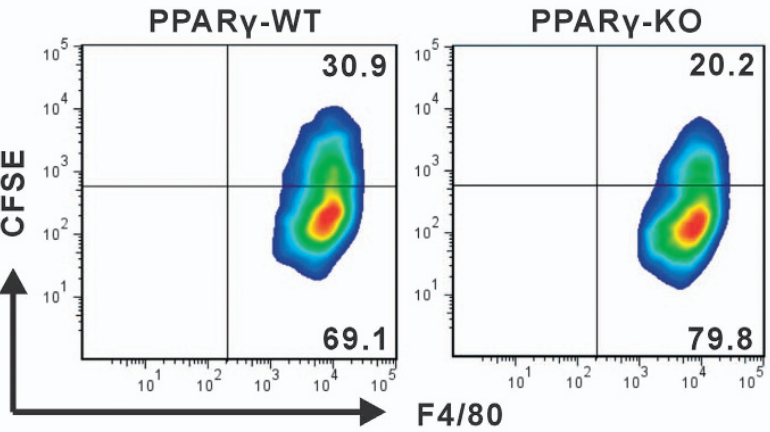

$\mathrm{F} 4 / 80$
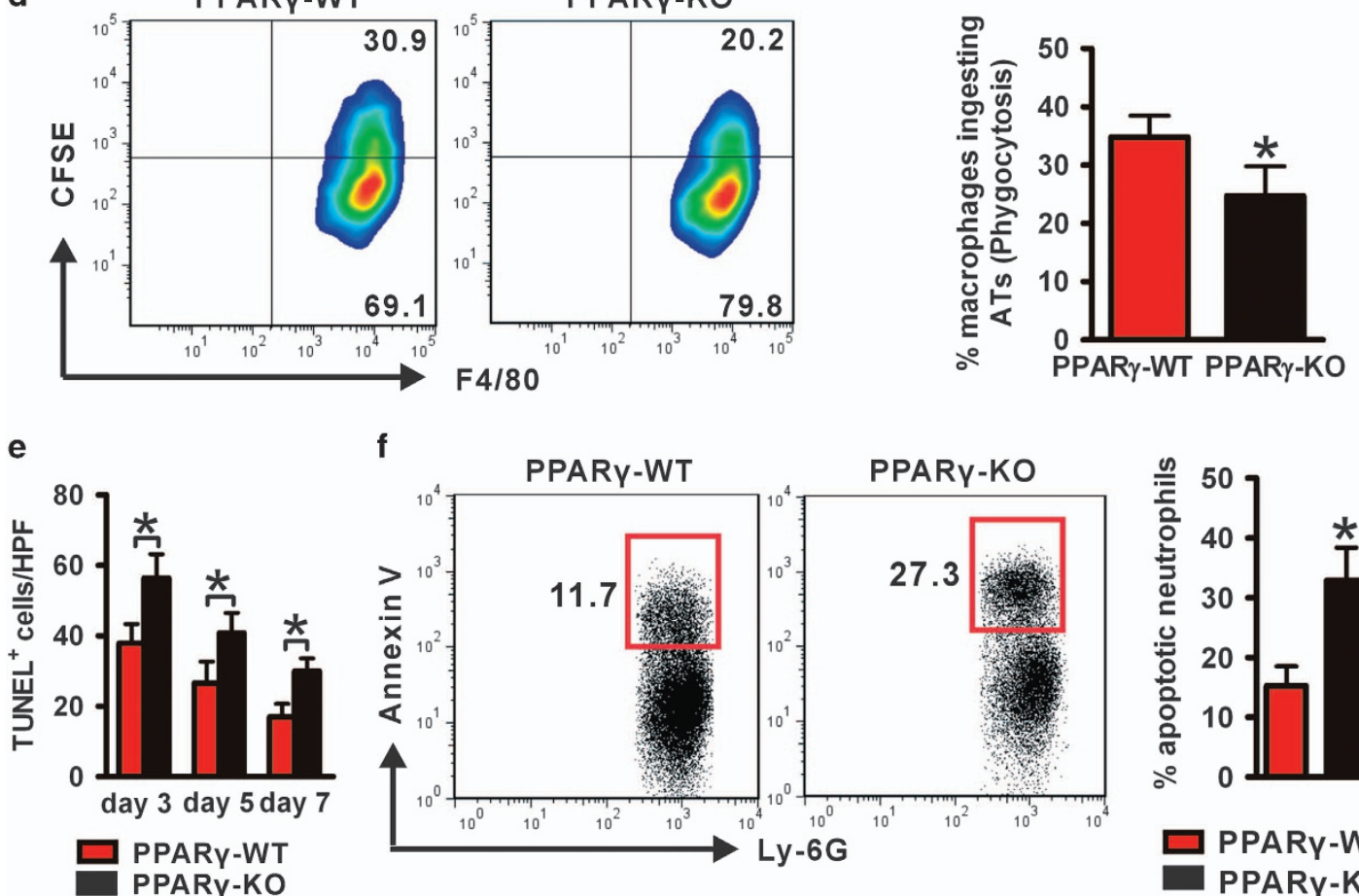

f
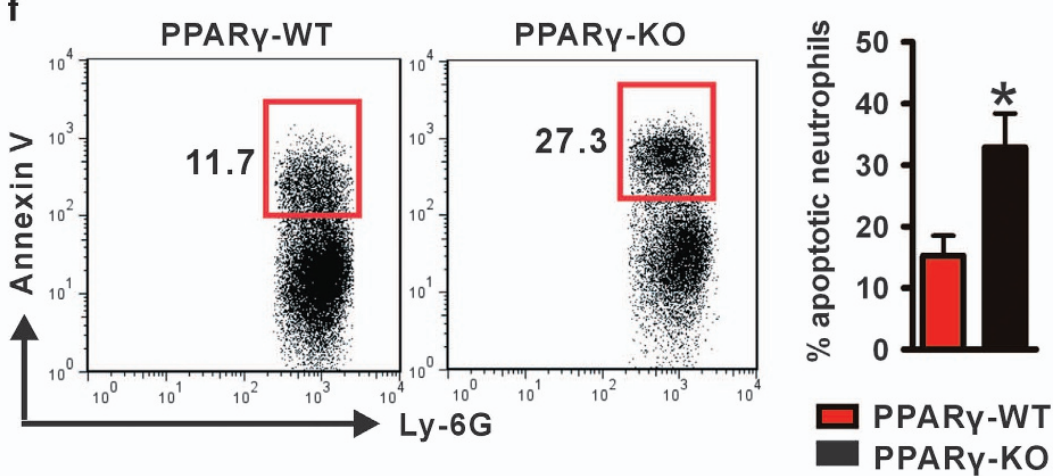

Figure 6 Increased production of TNF- $\alpha$ is due to impaired macrophage phagocytosis in PPAR $\gamma$-KO mice. (a) Intracellular staining for TNF- $\alpha$ in wound macrophages derived from PVA sponges after 5 days implantation. F4/80+ was used to gate macrophages. Isotype control, gray histogram; TNF- $\alpha$, unshaded histogram (red histogram: PPAR $\gamma$-WT; black histogram: PPAR $\gamma$-KO). Mean fluorescence intensity (MFI) is shown. The mRNA (b) and protein (c) levels of TNF- $\alpha$ in PPAR $\gamma$-WTand PPAR $\gamma$-KO peritoneal macrophages, and in ATs. ${ }^{*} P<0.05$. ${ }^{\#} P<0.05$, ATs versus PPARr-WT or PPAR - KO macrophages stimulated by LPS. (d) Representative flow cytometric raw data of the phagocytosis assays (macrophages were stained using F4/80 PE Ab; ATs were loaded with CFSE), and the percentages of macrophages ingesting ATs. (e) Quantification of TUNEL ${ }^{+}$cells in 3-, 5- and 7-day-old wounds in 3-5 high-power fields (HPFs) per mice. (f) The percentages of apoptotic neutrophils in total wound cells derived from PVA sponges after day 3 inserting. Data are expressed as mean \pm S.D. and images are representative, $n=3$ for each time point and group. For $(\mathbf{a}),(\mathbf{d}),(\mathbf{e})$ and $(\mathbf{f}),{ }^{*} P<0.05$, PPAR $\gamma-\mathrm{WT}$ versus PPAR $\gamma-\mathrm{KO}$ mice 
a

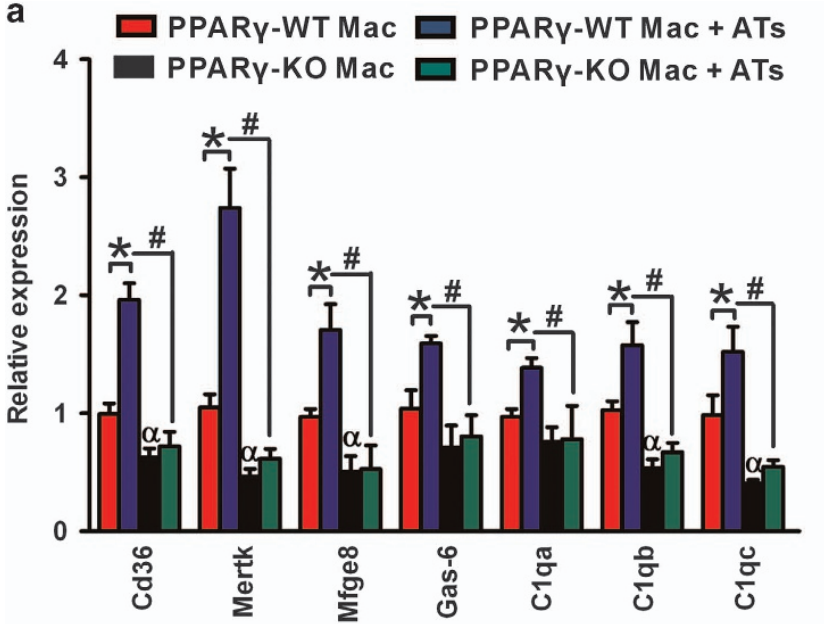

C $\square$ PPARY-WT Mac
PPARY-KO Mac

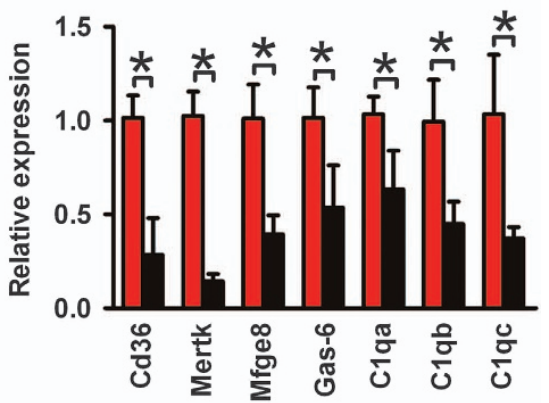

b
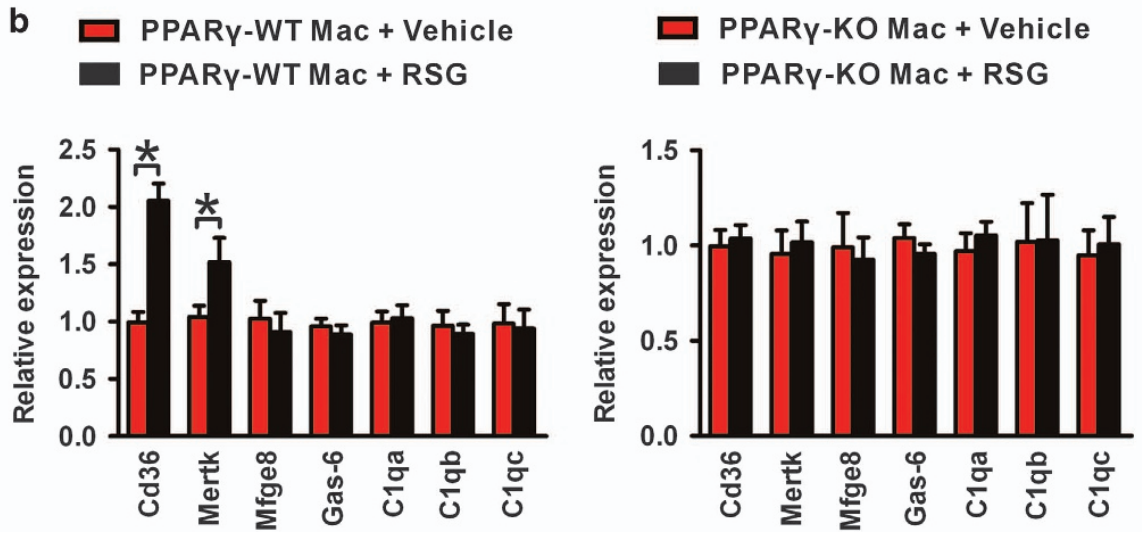

Figure 7 PPAR $\gamma$ regulate the expression of macrophages receptors and opsonins involved in the engulfment of apoptotic cells. (a) mRNA expression of phagocytosis-related genes in peritoneal macrophages not added ATs or added ATs. (b) mRNA expression of phagocytosis-related genes in peritoneal macrophages treated with vehicle (ethanol) or RSG. (c) mRNA expression of phagocytosis-related genes in wound macrophages derived from PVA sponges after 5 days implantation. ${ }^{\star} P<0.05$. ${ }^{\#} P<0.05$. ${ }^{\alpha} P<0.05, P P A R \gamma$ $\mathrm{KO}$ macrophages versus PPARy-WT macrophages. mRNA expression is normalized by $\beta$-actin, and gene expression is represented as fold change compared with PPAR $\gamma$-WT macrophages, or PPARy-WT or PPAR $y$-KO macrophages treated with Vehicle. Results are expressed as mean \pm S.D., $n=3$ for each group

impaired skin wound healing in PPARY-KO mice. Next, we observed that PPARY-KO wound macrophages released more TNF-a compared with their control macrophages. Furthermore, PPAR $y$ deficiency impaired macrophage phagocytosis of apoptotic cells through downregulating phagocytosisrelated molecules in macrophage, resulting in excessive TNF- $a$ expression by PPARY-KO macrophages. Meanwhile, increased apoptotic cells accumulation in PPARY-KO wounds was observed. These results directly or indirectly demonstrated that the impaired macrophage phagocytosis contributes to the excessive TNF- $a$ in wound of PPARy-KO mice. Therefore, macrophage PPAR $y$ deficiency decreased the expression of phagocytosis-related molecules, leading to deficit in clearance of apoptotic cells, resulting in impaired skin wound healing.

The timely and efficient clearance of apoptotic cells by macrophages is the key to skin wound healing. ${ }^{11}$ Macrophage phagocytosis of apoptotic cells prevents further tissue damage by protecting tissue from exposure to toxic components of dying cells, and suppresses the production of pro-inflammatory cytokines, and enhancing the expression of anti-inflammatory cytokines and growth factors, resulting in resolution of wound inflammation and promoting wound healing. ${ }^{42,43}$ Deficit in macrophage phagocytosis function during wound healing are related with chronic, non-healing wounds. ${ }^{13-15}$ Our study provides the first evidence of PPARy regulating wound macrophage phagocytosis function during skin wound healing. In addition, PPARy deficiency resulted in impaired macrophage phagocytosis function, contributing to delayed wound closure, which is consistent with the importance of apoptotic cell clearance in wound healing. Although several studies have observed macrophage phagocytosis deficit in chronic, non-healing wounds, ${ }^{13-15}$ the regulatory mechanisms underlying wound macrophage phagocytosis function are not fully deciphered. Differ from adhesion molecule $\beta_{2}$ integrins, which mediate adhesion-dependent phagocytosis of apoptotic cells by wound macrophages, ${ }^{28,31}$ PPAR $y$, as a nuclear transcription factor, transcriptionally regulates wound macrophage phagocytosis function. This finding may explain the poor wound healing in patients with chronic granulomatous disease, because macrophages from mice with chronic granulomatous disease have low levels of 
a
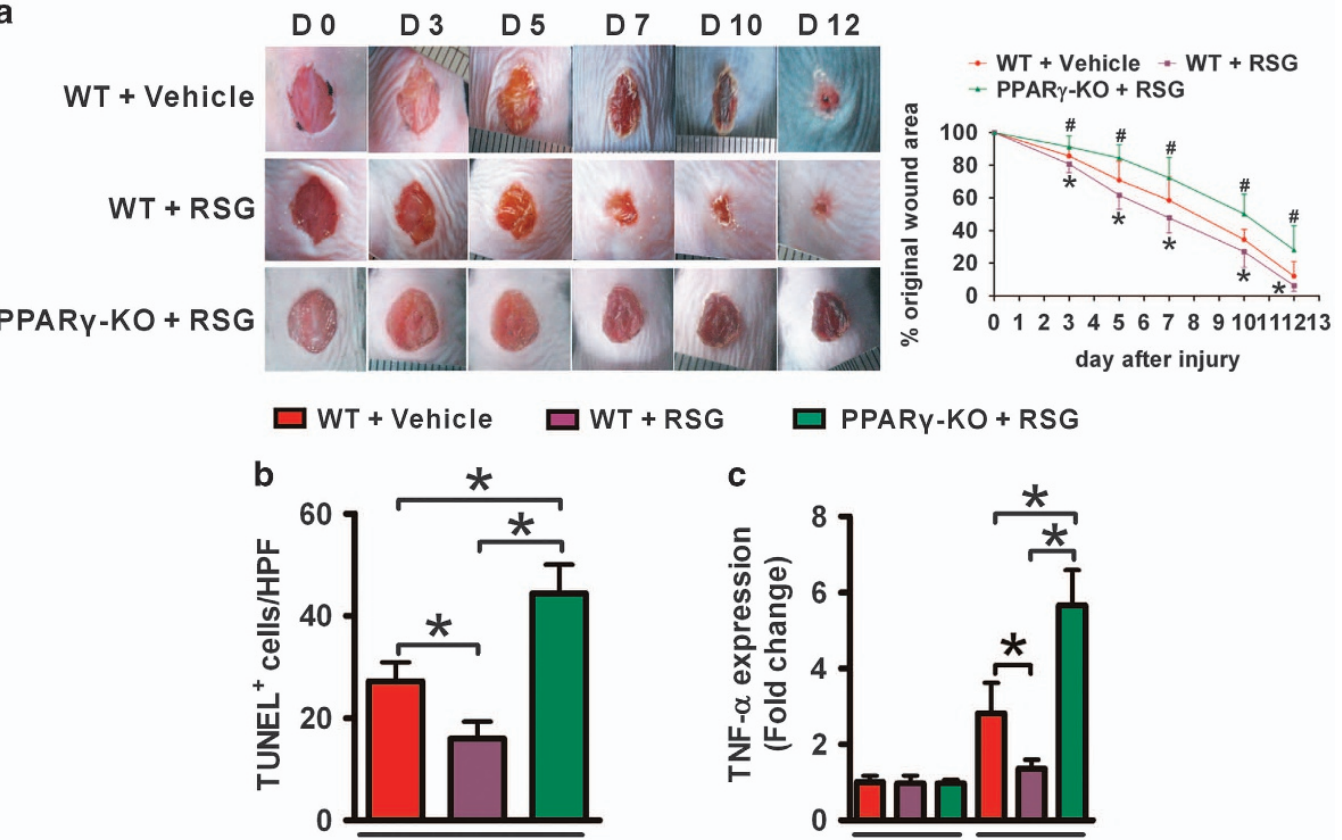

day 5

C

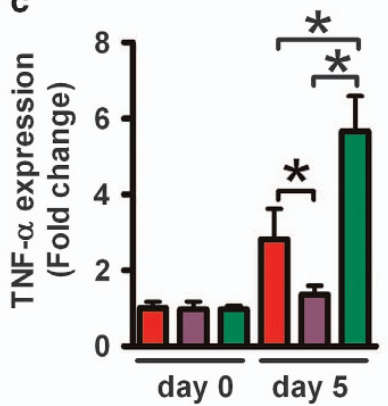

d

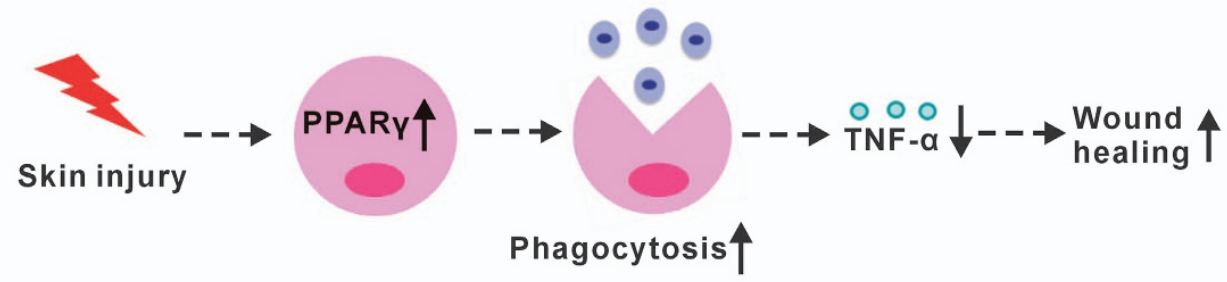

:Macrophages $\bullet:$ : Apoptotic cells $0:$ TNF- $\alpha$

Figure 8 PPAR $\gamma$ agonist accelerates wound healing in WT mice and suppresses apoptotic cell aggregation and TNF- $\alpha$ production in wounds, but not in PPAR $\gamma$-KO mice. (a) Representative wounds, and statistical analysis of wound areas expressed as percentage of the initial (day 0 ) wound size. $n=12$, for each time point and group. ${ }^{*} P<0.05$, RSG-treated WT mice versus vehicle-treated WT mice; ${ }^{\#} P<0.05$, RSG-treated PPAR $\gamma$-KO mice versus vehicle-treated WT mice. (b) Quantification of TUNEL ${ }^{+}$cells in 5-day-old wounds in 3-5 high-power fields (HPFs) per mice. (c) mRNA expression of TNF- $\alpha$ in normal skin and 5-day-old wounds. Both (b and $\mathbf{c}$ ), $n=3$ for each time point and group. All data are expressed as mean \pm S.D. ${ }^{*} P<0.05$. (d) After tissue injury, wound macrophage PPAR $\gamma$ is upregulated to timely disposal of apoptotic cells, resulting in decreased local TNF- $\alpha$ expression to enhancing wound healing

PPARy expression, ${ }^{44}$ or poor wound healing in patients with other diseases present macrophage PPARy low expression, and future studies are sure to test them.

Among all the tested macrophages phagocytosis-related molecules in our investigation, PPARy consistently affected the expression of $\mathrm{Cd} 36$ and Mertk in PPARY-KO macrophages. Although Cd36 is well known to be upregulated by PPAR $y$ activation, the regulation of Mertk by PPARy has been reported. ${ }^{45,46}$ However, the expression of Mertk is induced by activating liver $X$ receptor $(L X R),{ }^{47}$ and activating PPAR $y$ will upregulate $L X R,{ }^{48}$ suggesting that Mertk expression may be induced by PPAR $y$ via LXR.

TNF- $a$ is a key factor impacting the healing process. ${ }^{35,37}$ Excessive TNF- $a$ expression in wound impaired the functions of keratinocytes, fibroblasts and endothelial cells, ${ }^{37,49,50}$ resulting in reduced reepithelialization, collagen deposition, angiogenesis and granulation tissue formation, and severely delayed wound healing. ${ }^{34,36}$ Our results showed wound $P P A R Y-K O$ macrophages released excessive TNF- $a$, contributing to higher TNF- $a$ expression in wounds, resulting in impaired wound healing in PPARY-KO mice. Although in chronic, non-healing wounds, high expression of TNF- $a$ by wound macrophages were observed, the underlying mechanisms are not fully known. However, the phagocytosis of apoptotic cells is associated with an anti-inflammatory response, such as suppressing TNF- $a$ expression, in macrophages and the failure of apoptotic cell clearance is associated with chronic wound, suggesting the involvement of apoptotic cell engulfment in TNF- $a$ expression regulation in skin wound. Here, we revealed that PPARy regulates skin wound macrophages TNF- $a$ expression by orchestrating their phagocytic function. It is well established that apoptotic cells are digested and cellular components, such as cholesterol and fatty acids, are released after engulfed by macrophages. These cellular components are ligands for PPAR $\gamma$, which may induce PPAR $\gamma$ sumoylation to attenuate the removal of nuclear receptor corepressor from the $\kappa \mathrm{B}$ site within the TNF- $a$ promoter, resulting in blocking the transactivation of $\mathrm{NF}-k \mathrm{~B}$ and reducing 
TNF- $a$ production in macrophages. ${ }^{51}$ Therefore, PPAR $y$ can directly contribute to the TNF- $a$ expression regulation induced by apoptotic cell engulfment. Correspondingly, the increased engulfment of apoptotic cells may enhance PPAR $y$ activation to suppress TNF- $a$ production. Our data here showed that PPARy enhanced phagocytosis of apoptotic cells through increasing the expression of macrophage phagocytosisrelated molecules, especially CD36 and Mertk, suggesting that PPARy may also indirectly reduce TNF- $a$ expression via upregulation of CD36 and Mertk.

Although our study here clearly showed that PPARy was important for regulating wound macrophage phagocytosis function, the contribution of PPARy to skin wound healing remains controversial. Previous studies showed that in fibroblasts, PPARy agonists block TGF- $\beta$-induced $a$ SMA, which is a myofibroblast differentiation marker and collagen expression, ${ }^{52,53}$ and deletion of PPARy in fibroblasts enhances dermal wound closure, indicating that PPARy acts in fibroblasts retarding tissue repair. However, our results showed that PPARy upregulated in wounded skin, which is consistent with previous study ${ }^{54}$ and in wound macrophages, and mice with macrophage PPAR $y$ deficiency severely impaired wound healing, suggesting that PPARy has a regulatory role in wound healing and acts in macrophages enhancing the healing process. Despite the controversial roles of PPARy in macrophages and fibroblasts during wound healing, our data showed that PPARy agonist accelerated the wound healing in WT but not PPARY-KO mice, suggesting that PPARy agonist accelerated wound healing because of activating macrophages PPAR $y$. So we concluded that activating PPARy is helpful for improving skin wound healing.

In summary, our studies elucidated the pathophysiological mechanism of macrophage PPARy in skin wound healing. After tissue injury, macrophage PPARy is upregulated to promote timely disposal of apoptotic cells through increased the phagocytosis-related molecules expression, contributing to decreased local TNF- $a$ expression to enhancing tissue repair (Figure 8d). Furthermore, we showed that activating PPARy accelerated normal wound healing, providing the evidence of PPARy may be a candidate for treatment of wound healing.

\section{Materials and Methods}

Mice. C57BL/6J male mice (8-12 weeks) were purchased from the Animal Center, Research Institute of Surgery and Daping hospital, TMMU, Chongqing, China. Mice carrying floxed alleles of PPARy (PPAR $\gamma^{\text {t/h }}$ ) and mice bearing the lysozyme-M Cre (LysMCre) recombinase transgene were purchased from the Jackson Laboratory (Mount Desert Island, ME, USA). PPARY ${ }^{\text {f/f }}$ mice and LysMCre mice were crossed to generate offspring with macrophage-specific deficiency of the PPARy gene. The PPARy $\gamma^{t / 4} L y s M C r e^{-}$mice (PPARy-WT) were used as WT control as previous reports and PPARy $\gamma^{t / f} L y s M C r e^{+}$mice are referred to as PPARy-KO mice. ${ }^{22,55}$ All mice were on a C57BL/6 background and housed under a 12-h light12-h dark cycle with free access to food and water. Wound-healing experiments were performed with male mice between 8 and 12 weeks of age. All animal procedures were in accordance with a protocol approved by the Local Administration District Official Committee. All efforts were made to minimize the number of animals and their suffering.

Analyses of macrophage-specific PPARy deficient mice. The genotyping of determining PPARy-WT and PPAR $\gamma$-KO mice was performed by PCR of DNA obtained from tail biopsies. Primary peritoneal macrophages were recovered from mice injected with $3 \%$ thyoglicolate for 3 days. The mRNA levels and protein expression of PPAR $\gamma$ in both macrophage strains were performed by
RT-PCR and WB. PPAR $\gamma$ expression in isolated wound macrophages and neutrophils, and splenic T cells, B cells and dendritic cells were analyzed by flow cytometry.

Wound-healing model. Full-thickness (including the panniculus carnosus) wounds were created in the dorsal skin under sterile conditions. Briefly, mice were anesthetized with peritoneal injection (i.p.) with pentobarbital sodium $(50 \mathrm{mg} / \mathrm{kg}$; Boster, Wuhan, China). After depilation with $8 \% \mathrm{Na}_{2} \mathrm{~S}$ and cleaning with povidoneiodine and $75 \%$ ethanol, the dorsal skin was picked up at the midline and punched with a sterile disposable biopsy punch $(6 \mathrm{~mm}$ in diameter; Miltex, New York, NY, USA), generating one wound on the midline or two wounds on each side of the midline. One or four wounds per mice were induced. At indicated time points, each wound was digitally photographed, and wound areas were quantified using CoreIDRAW 9 (Corel Software, Oakland, CA, USA). Changes in wound areas over time were expressed as the percentage of initial (day 0 ) wound area.

PVA sponges implantation and wound cell isolation. Mice were anesthetized with pentobarbital (50 mg/kg i.p.) and dorsal skin was depilated. Six PVA sponges (unlimited), measuring $1 \times 1 \times 0.6 \mathrm{~cm}$, were inserted into individual s.c. pockets through a midline dorsal incision under sterile condition, and the skin was closed with clips. ${ }^{56}$ At specified times, mice were killed by $\mathrm{CO}_{2}$ asphyxiation, and the sponges were removed and a single-wound cell suspension was generated from sponges by repeated compression. The cell suspension was filtered through a $70 \mu \mathrm{m}$ nylon cell strainer (Falcon, Shanghai, China) to remove all the sponge debris. When necessary, cells were subjected to red cell lysis buffer (Invitrogen, San Diego, CA, USA), followed by reconstitution in PBS. The s.c. sponge model is extensively used for wound-healing studies especially those investigating wound inflammation. ${ }^{57-60}$ The primary difference between s.c. sponge model and excisional wound model is low-grade bacterial contamination of open wounds. ${ }^{61}$ Therefore, we routinely checked bacterial contamination in our excisional wounds using protocols described previously. ${ }^{62}$ As previous studies reported, although low-grade contamination was observed in superficial tissues, deep-tissue biopsies had not shown any bacterial contamination, suggesting that excisional deep-tissue wound cells are similar to that derived from PVA sponge. ${ }^{62}$

Total RNA isolation and quantitative RT-PCR. Total RNA was isolated using Tripure Isolation Reagent (Roche Group, Shanghai, China) and reverse transcribed into CDNA using Quantscript RT Kit (Tiangen Biotech, Beijing, China). The resulting cDNA was used to measure quantitatively the expression of genes using Quant Reverse Transcriptase according to the manufacturer's protocol (Tiangen Biotech, Beijing, China). Real-time measurements of gene expression were performed with an iCycler thermocycler system and iQ5 optical system software (Bio-Rad Laboratory, Richmond, CA, USA). All primers were synthesized by Invitrogen Technologies (Carlsbad, CA, USA) and primer sequences used are presented as follows: $\beta$-actin (forward, $5^{\prime}$-TGGAATCCTGTGGCATCCATGAAA-3'; reverse, 5'-TAAAACGCAGCTCAGTAACAGTCCG-3'), PPAR $\gamma$ (forward, 5'-TATCA CTGGAGATCTCCGCCAACAGC-3'; reverse, 5'-GTCACGTTCTGACAGGACTGT GTGAC-3'), collagen type 1 (forward, 5'-ATCACTGCAAGAACAGCGTA-3'; reverse, 5'-TGTTTTCCAAAGTCCATGTG-3'), VEGF (forward, 5'-TGGATGTCTACCAGCG AAGC-3'; reverse, $5^{\prime}$-ACAAGGCTCACAGTGATTTT-3'), TNF- $\alpha$ (forward, $5^{\prime}$-AACTA GTGGTGCCAGCCGAT-3'; reverse, 5'-CTTCACAGAGCAATGACTCC-3'), Cd36 (forward, 5'-TCGGAACTGTGGGCTCATTG-3'; reverse, 5'-CCTCGGGGTCC TGAGTTATATTTTC- $3^{\prime}$ ), Mertk (forward, 5'-GTGGCAGTGAAGACCATGAAGTT G-3'; reverse, 5'-GAACTCCGGGATAGGGAGTCAT-3'), Gas6 (forward, 5'-TCTT CTCACACTGTGCTGTTGCG-3'; reverse, 5'-GGTCAGGCAAGTTCTGAACACAT -3'), Mfge8 (forward, 5'-GGACATCTTCACCGAATACATCTGC-3'; reverse, 5'-TGA TACCCGCATCTTCCGCAG-3'), C1qa (forward, 5'-AAAGGCAATCCAGGCAATATC A-3'; reverse, 5'-TGGTTCTGGTATGGACTCTCC-3'), C1qb (forward, 5'-AACGCGA ACGAGAACTATGA-3'; reverse, 5'-ACGAGATTCACACACACAGGTTG-3') and C1qc (forward, 5'-CAACGCCCTCGTCAGGTT-3'; reverse, 5'-ACAACCCAAGC ACAGGGAAGT-3'). The RT-PCR data were analyzed by the method of $2^{-\Delta \Delta C t}$ and the data were normalized to $\beta$-actin.

Western blotting. Wound tissues and cultured cells were homogenized in icecold RIPA with $1 \mathrm{mg} / \mathrm{ml}$ of a protease inhibitor cocktail (Beyotime, Shanghai, China). The homogenates were centrifuged at 14000 r.p.m. for $5 \mathrm{~min}$ at $4^{\circ} \mathrm{C}$ and supernatants were collected. Subsequently, BCA assays were performed to determine the protein concentration of the supernatants. Standard protocol was used and following antibodies were applied: PPAR $\gamma$ (Abcam Inc., San Francisco, 
CA, USA), TNF- $\alpha$ (Santa Cruz Biotechnology, Santa Cruz, CA, USA), GAPDH (Goodhere Biotechnology, Hangzhou, China), the goat anti-rabbit lgG-HRP secondary antibody (Novus Biologicals, Littleton, CO, USA) and the goat antimouse IgG-HRP secondary antibody (Beyotime). The blots were detected by chemiluminescence with enhanced chemiluminescence reagent (BeyoECL Plus, Beyotime).

Histology. Wounded tissues were harvested, fixed in $4 \%$ paraformaldehyde, dehydrated, bisected, mounted in paraffin and sectioned for H\&E staining, Masson trichrome staining and immunohistochemistry. Granulation tissues were stained using H\&E. Collagen was stained with Masson trichrome. Immunohistochemistry was carried out with following antibodies: PPAR $\gamma$ (Abcam Inc.), F4/80 (Abcam Inc.), Ly-6G (eBioscience, San Diego, CA, USA), CD31 (Boster), the goat anti-rat IgGbiotin secondary antibody (Invitrogen) and the goat anti-rabbit lgG-biotin secondary antibody (Invitrogen). The protocol used for immunohistochemistry was performed as reported previously. ${ }^{63}$ Briefly, paraffin-embedded tissue blocks were cut into $4 \mu \mathrm{m}$ sections. After the sections were dewaxed and rehydrated, antigen retrieval was performed by microwaving in citrate buffer $(\mathrm{pH} 6.0)$. The sections were cooled to room temperature (RT), and endogenous peroxidase activity was blocked by incubation with $3 \%$ hydrogen peroxidase $\left(\mathrm{H}_{2} \mathrm{O}_{2}\right)$ for $10 \mathrm{~min}$. The sections were incubated with $3 \%$ albumin boving $V$ to block nonspecific binding at RT. Thereafter, the sections were incubated with primary antibodies overnight at $4^{\circ} \mathrm{C}$. After washing, the sections were incubated with corresponding secondary antibodies for 30 min at RT. Subsequently, the Vecta-stain ABC kit (Vector Laboratories, San Diego, CA, USA) was used for the avidin-biotin complex method according the manufacturer's instruction. Peroxidase activity was visualized with DAB Elite kit (K3465, DAKO, Copenhagen, Denmark). The sections were lightly counterstained with hematoxylin and dehydrated through an ethanol series to xylene and mounted.

Tunel staining was performed using a commercially available kit (Derma TACS, Trevigen Inc., Gaithersburg, MD, USA).

All the sections were viewed using a light and fluorescence microscope. For image quantification, 3-5 high-powered images were quantified for each data point per animal.

Local TNF- $a$ restoration and PPAR $y$ agonist treatment. In TNF- $\alpha$ restoration experiments, wound margins were s.c. injected with $10 \mu \mathrm{g}$ per wound purified aTNF- $\alpha$ (Sungene, Tianjin, China) on days 3, 4, 5, 6 and 7 after wounding. Mice treated with isotype control antibody (Sungene) served as mock controls. For PPAR $\gamma$ agonist RSG (Sigma Aldrich, St. Louis, MO, USA) treatment, mice were given RSG $(10 \mathrm{mg} / \mathrm{kg}$ ) or vehicle (carboxymethyl cellulose) (Sangon Biotech, Shanghai, China) via oral gavage for 2 days before wounding and every day thereafter until day 12 after wounding.

Gene expression and cytokine secretion assays. Primary peritoneal macrophages were collected from abdomen of mice, which were injected with $3 \%$ thyoglicolate for 3 days. Cells were incubated in RPMI 1640 medium supplemented with $10 \%$ FCS. To generate ATs, thymi from 3- to 4- week-old C57BL/6 mice were harvested and ground, filtered, pelleted and resuspended in RPMI 1640 medium supplemented with $10 \%$ FCS. Apoptosis was induced by treatment with $1 \mu \mathrm{M}$ of dexamethasone (Sigma Aldrich) for $6 \mathrm{~h}$. For AT assays, ATs were added to macrophages $(5: 1)$ for $60 \mathrm{~min}$ or $24 \mathrm{~h}$. When needed, ATs were removed by gently washing, and macrophages were incubated with $100 \mathrm{ng} / \mathrm{ml} \mathrm{LPS} \mathrm{for} \mathrm{additional} 5 \mathrm{~h}$ for gene expression analysis and $18 \mathrm{~h}$ for cytokine secretion studies. For ligand assays, macrophages were incubated with $100 \mathrm{nM}$ RSG for $24 \mathrm{~h}$. Gene expression was performed by RT-PCR and cytokine secretion was quantified in culture supernatants using commercially available ELISA kits (BD Biosciences, Franklin Lakes, NJ, USA).

In vitro phagocytosis assays. CFSE-labeled ATs were added to peritoneal macrophages in a 5:1 ratio and co-cultured in RPMI supplemented with 10\% FBS at $37^{\circ} \mathrm{C}$ for $60 \mathrm{~min}$. After incubation with ATs, macrophages were gently washed several times with cold PBS and Cell Dissociation Buffer, Enzyme Free PBS-based (Invitrogen). A single-cell suspension of macrophages was stained with PEconjugated anti-mouse F4/80 antibody (Sungene Biotech, Tianjin, China) and cells were analyzed by flow cytometry.

Flow cytometric analyses of wound cells isolated from PVA sponges. Wound cells were isolated from PVA sponges at indicated time points. Antibodies used for cells staining included: Ly-6G, F4/80, CD11b, annexin V, antirabbit IgG (FITC-conjugated secondary antibody) all from Sungene Biotech; PPAR $\gamma$ from Abcam Inc.; TNF- $\alpha$ and normal rabbit IgG from Santa Cruz Biotechnology. Cells were analyzed with a FACScan (BD Biosciences). Flow cytometry analysis was done with the FlowJo software (FlowJo, Hangzhou, China).

Flow cytometric analyses of splenic $\mathrm{T}$ cells, B cells and dendritic cells. The spleen was cut from abdomen and ground, and erythrocytes were lysed with red cell lysis buffer. The cells were then resuspended in PBS. Antibodies used for cells staining included: CD3, CD4, CD8, CD19, CD11b, CD11c, anti-rabbit IgG (FITC-conjugated secondary antibody) all from Sungene Biotech; PPAR $\gamma$ from Abcam Inc.; normal rabbit IgG from Santa Cruz Biotechnology. Cells were analyzed with a FACScan. Flow cytometry analysis was done with the FlowJo software.

Statistical analysis. Data were statistically analyzed using GraphPadPrism 5.0 (GraphPad Software, Beijing, China) and expressed as the mean \pm S.D. for the indicated number of independently performed duplicated experiments. Statistical significance was determined by two-tailed Student's $t$-test. For all statistical analyses, significance levels were set at $P$-values $<0.05$.

\section{Conflict of Interest}

The authors declare no conflict of interest.

Acknowledgements. This investigation was supported by the National Natural Science Foundation of China (31170851 and 81471570) and the SRF for ROCS, SEM.

1. Mahdavian Delavary B, van der Veer WM, van Egmond M, Niessen FB, Beelen RH. Macrophages in skin injury and repair. Immunobiology 2011; 216: 753-762.

2. Li J, Chen J, Kirsner R. Pathophysiology of acute wound healing. Clin Dermatol 2007; 25: 9-18.

3. Singer AJ, Clark RA. Cutaneous wound healing. N Engl J Med 1999; 341: 738-746.

4. Sen CK, Gordillo GM, Roy S, Kirsner R, Lambert L, Hunt TK et al. Human skin wounds: a major and snowballing threat to public health and the economy. Wound Repair Regen 2009; 17: 763-771.

5. Natarajan S, Williamson D, Stiltz AJ, Harding K. Advances in wound care and healing technology. Am J Clin Dermatol 2000; 1: 269-275.

6. Martin JM, Zenilman JM, Lazarus GS. Molecular microbiology: new dimensions for cutaneous biology and wound healing. J Invest Dermatol 2010; 130: 38-48.

7. Mirza R, DiPietro LA, Koh TJ. Selective and specific macrophage ablation is detrimental to wound healing in mice. Am J Pathol 2009; 175: 2454-2462.

8. Lucas T, Waisman A, Ranjan R, Roes J, Krieg T, Muller W et al. Differential roles of macrophages in diverse phases of skin repair. J Immunol 2010; 184: 3964-3977.

9. Koh TJ, DiPietro LA. Inflammation and wound healing: the role of the macrophage. Exp Rev Mol Med 2011; 13: e23.

10. Stout RD. Editorial: macrophage functional phenotypes: no alternatives in dermal wound healing? J Leukoc Biol 2010; 87: 19-21.

11. Wu YS, Chen SN. Apoptotic cell: linkage of inflammation and wound healing. Front Pharmacol 2014; 5: 1.

12. Rodero MP, Khosrotehrani K. Skin wound healing modulation by macrophages. Int J Clin Exp Pathol 2010; 3: 643-653.

13. Khanna S, Biswas S, Shang Y, Collard E, Azad A, Kauh C et al. Macrophage dysfunction impairs resolution of inflammation in the wounds of diabetic mice. PloS One 2010; 5: e9539.

14. Tang Y, Zhang MJ, Hellmann J, Kosuri M, Bhatnagar A, Spite M. Proresolution therapy for the treatment of delayed healing of diabetic wounds. Diabetes 2013; 62: 618-627.

15. Swift ME, Burns AL, Gray KL, DiPietro LA. Age-related alterations in the inflammatory response to dermal injury. J Invest Dermatol 2001; 117: 1027-1035.

16. Michalik L, Desvergne B, Tan NS, Basu-Modak S, Escher P, Rieusset J et al. Impaired skin wound healing in peroxisome proliferator-activated receptor (PPAR)alpha and PPARbeta mutant mice. J Cell Biol 2001; 154: 799-814.

17. Tan NS, Michalik L, Desvergne B, Wahli W. Peroxisome proliferator-activated receptor (PPAR)-beta as a target for wound healing drugs: what is possible? Am J Clin Dermatol 2003; 4: 523-530.

18. Tan NS, Michalik L, Di-Poi N, Desvergne B, Wahli W. Critical roles of the nuclear receptor PPARbeta (peroxisome-proliferator-activated receptor beta) in skin wound healing. Biochem Soc Transac 2004; 32: 97-102.

19. Li J, Li P, Zhang Y, Li GB, He FT, Zhou YG et al. Upregulation of ski in fibroblast is implicated in the peroxisome proliferator-activated receptor delta-mediated wound healing. Cell Physiol Biochem 2012; 30: 1059-1071.

20. Rigamonti E, Chinetti-Gbaguidi G, Staels B. Regulation of macrophage functions by PPARalpha, PPAR-gamma, and LXRs in mice and men. Arterioscler Thromb Vasc Biol 2008; 28: 1050-1059.

21. Majai G, Sarang Z, Csomos K, Zahuczky G, Fesus L. PPARgamma-dependent regulation of human macrophages in phagocytosis of apoptotic cells. Eur $J$ Immunol 2007; 37: 1343-1354. 
22. Roszer T, Menendez-Gutierrez MP, Lefterova Ml, Alameda D, Nunez V, Lazar MA et al. Autoimmune kidney disease and impaired engulfment of apoptotic cells in mice with macrophage peroxisome proliferator-activated receptor gamma or retinoid $\mathrm{X}$ receptor alpha deficiency. J Immunol 2011; 186: 621-631.

23. Asada K, Sasaki S, Suda T, Chida K, Nakamura H. Antiinflammatory roles of peroxisome proliferator-activated receptor gamma in human alveolar macrophages. Am J Respir Crit Care Med 2004; 169: 195-200.

24. Odegaard JI, Ricardo-Gonzalez RR, Goforth MH, Morel CR, Subramanian V, Mukundan L et al. Macrophage-specific PPARgamma controls alternative activation and improves insulin resistance. Nature 2007; 447: 1116-1120.

25. Low QE, Drugea IA, Duffner LA, Quinn DG, Cook DN, Rollins BJ et al. Wound healing in MIP-1alpha(-/-) and MCP-1(-/-) mice. Am J Pathol 2001; 159: 457-463.

26. Martin P, D'Souza D, Martin J, Grose R, Cooper L, Maki R et al. Wound healing in the PU.1 null mouse-tissue repair is not dependent on inflammatory cells. Curr Biol 2003; 13 $1122-1128$.

27. Martin P, Leibovich SJ. Inflammatory cells during wound repair: the good, the bad and the ugly. Trends Cell Biol 2005; 15: 599-607.

28. Peters T, Sindrilaru A, Hinz B, Hinrichs R, Menke A, Al-Azzeh EA et al. Wound-healing defect of CD18(-/-) mice due to a decrease in TGF-beta1 and myofibroblast differentiation. EMBO J 2005; 24: 3400-3410.

29. Maruyama K, Asai J, li M, Thorne T, Losordo DW, D'Amore PA. Decreased macrophage number and activation lead to reduced lymphatic vessel formation and contribute to impaired diabetic wound healing. Am J Pathol 2007; 170: 1178-1191.

30. Ishida Y, Gao JL, Murphy PM. Chemokine receptor CX3CR1 mediates skin wound healing by promoting macrophage and fibroblast accumulation and function. J Immunol 2008; 180 : 569-579.

31. Sindrilaru A, Peters T, Schymeinsky J, Oreshkova T, Wang H, Gompf A et al. Wound healing defect of Vav3-/- mice due to impaired \{beta\}2-integrin-dependent macrophage phagocytosis of apoptotic neutrophils. Blood 2009; 113: 5266-5276.

32. Goldberg MT, Han YP, Yan C, Shaw MC, Garner WL. TNF-alpha suppresses alpha-smooth muscle actin expression in human dermal fibroblasts: an implication for abnormal wound healing. J Invest Dermat 2007; 127: 2645-2655.

33. Siqueira MF, Li J, Chehab L, Desta T, Chino T, Krothpali N et al. Impaired wound healing in mouse models of diabetes is mediated by TNF-alpha dysregulation and associated with enhanced activation of forkhead box 01 (FOXO1). Diabetologia 2010; 53 378-388.

34. Lai JJ, Lai KP, Chuang KH, Chang P, Yu IC, Lin WJ et al. Monocyte/macrophage androgen receptor suppresses cutaneous wound healing in mice by enhancing local TNF-alpha expression. J Clin Invest 2009: 119: 3739-3751.

35. Ashcroft GS, Jeong MJ, Ashworth JJ, Hardman M, Jin W, Moutsopoulos N et al. Tumo necrosis factor-alpha (TNF-alpha) is a therapeutic target for impaired cutaneous wound healing. Wound Repair Regen 2012; 20: 38-49.

36. Sindrilaru A, Peters T, Wieschalka S, Baican C, Baican A, Peter $\mathrm{H}$ et al. An unrestrained proinflammatory M1 macrophage population induced by iron impairs wound healing in humans and mice. J Clin Invest 2011; 121: 985-997.

37. Xu F, Zhang C, Graves DT. Abnormal cell responses and role of TNF-alpha in impaired diabetic wound healing. BioMed Res Int 2013; 2013: 754802.

38. Werner S, Grose R. Regulation of wound healing by growth factors and cytokines. Physio Rev 2003; 83: 835-870.

39. Weigert A, Jennewein $C$, Brune $B$. The liaison between apoptotic cells and macrophagesthe end programs the beginning. Biol Chem 2009; 390: 379-390.

40. Hart SP, Smith JR, Dransfield I. Phagocytosis of opsonized apoptotic cells: roles for 'old-fashioned' receptors for antibody and complement. Clin Exp Immunol 2004; 135 $181-185$

41. Kliewer SA, Xu HE, Lambert MH, Willson TM. Peroxisome proliferator-activated receptors: from genes to physiology. Recent Prog Horm Res 2001; 56: 239-263.

42. Erwig LP, Henson PM. Clearance of apoptotic cells by phagocytes. Cell Death Differ 2008; 15: 243-250.

43. Galli SJ, Borregaard N, Wynn TA. Phenotypic and functional plasticity of cells of innate immunity: macrophages, mast cells and neutrophils. Nat Immunol 2011; 12: 1035-1044.

44. Fernandez-Boyanapalli RF, Frasch SC, McPhillips K, Vandivier RW, Harry BL, Riches DW et al Impaired apoptotic cell clearance in CGD due to altered macrophage programming is reversed by phosphatidylserine-dependent production of IL-4. Blood 2009; 113: 2047-2055.
45. Feng J, Han J, Pearce SF, Silverstein RL, Gotto AM Jr., Hajiar DP et al. Induction of CD36 expression by oxidized LDL and IL-4 by a common signaling pathway dependent on protein kinase $C$ and PPAR-gamma. J Lipid Res 2000; 41: 688-696.

46. McCarty MF, Barroso-Aranda J, Contreras F. PPAR gamma agonists can be expected to potentiate the efficacy of metronomic chemotherapy through CD36 up-regulation. Med Hypotheses 2008; 70: 419-423.

47. A-Gonzalez N, Bensinger SJ, Hong C, Beceiro S, Bradley MN, Zelcer N et al. Apoptotic cells promote their own clearance and immune tolerance through activation of the nuclear receptor LXR. Immunity 2009; 31: 245-258.

48. Piraino G, Cook JA, O'Connor M, Hake PW, Burroughs TJ, Teti D et al. Synergistic effect of peroxisome proliferator activated receptor-gamma and liver $X$ receptor-alpha in the regulation of inflammation in macrophages. Shock 2006; 26: 146-153.

49. Salomon GD, Kasid A, Cromack DT, Director E, Talbot TL, Sank A et al. The local effects of cachectin/tumor necrosis factor on wound healing. Ann Surg 1991; 214: 175-180.

50. Rapala K, Laato M, Niinikoski J, Kujari H, Soder O, Mauviel A et al. Tumor necrosis factor alpha inhibits wound healing in the rat. Eur Surg Res 1991; 23: 261-268.

51. Jennewein C, Kuhn AM, Schmidt MV, Meilladec-Jullig V, von Knethen A, Gonzalez FJ et al. Sumoylation of peroxisome proliferator-activated receptor gamma by apoptotic cells prevents lipopolysaccharide-induced $\mathrm{NCoR}$ removal from kappaB binding sites mediating transrepression of proinflammatory cytokines. J Immunol 2008; 181: 5646-5652.

52. Burgess HA, Daugherty LE, Thatcher TH, Lakatos HF, Ray DM, Redonnet M et al. PPARgamma agonists inhibit TGF-beta induced pulmonary myofibroblast differentiation and collagen production: implications for therapy of lung fibrosis. Am J Physiol Lung Cell Mol Physiol 2005; 288: L1146-L1153.

53. Wu M, Melichian DS, Chang E, Warner-Blankenship M, Ghosh AK, Varga J. Rosiglitazone abrogates bleomycin-induced scleroderma and blocks profibrotic responses through peroxisome proliferator-activated receptor-gamma. Am J Pathol 2009; 174: 519-533.

54. Kapoor M, Kojima F, Yang L, Crofford LJ. Sequential induction of pro- and anti-inflammatory prostaglandins and peroxisome proliferators-activated receptor-gamma during normal wound healing: a time course study. Prostag Leukotr Ess Fatty Acids 2007; 76: 103-112.

55. Hevener AL, Olefsky JM, Reichart D, Nguyen MT, Bandyopadyhay G, Leung HY et al. Macrophage PPAR gamma is required for normal skeletal muscle and hepatic insulin sensitivity and full antidiabetic effects of thiazolidinediones. J Clin Invest 2007; 117: 1658-1669.

56. Meszaros AJ, Reichner JS, Albina JE. Macrophage phagocytosis of wound neutrophils. $J$ Leukoc Biol 1999; 65: 35-42.

57. Albina JE, Mills CD, Barbul A, Thirkill CE, Henry Jr WL, Mastrofrancesco B et al. Arginine metabolism in wounds. Am J Physiol 1988; 254: E459-E467.

58. Efron DT, Barbul A. Subcutaneous sponge models. Methods Mol Med 2003; 78: 83-93.

59. Daley JM, Brancato SK, Thomay AA, Reichner JS, Albina JE. The phenotype of murine wound macrophages. J Leukoc Biol 2010; 87: 59-67.

60. Daley JM, Reichner JS, Mahoney EJ, Manfield L, Henry Jr WL, Mastrofrancesco B et al. Modulation of macrophage phenotype by soluble product(s) released from neutrophils. J Immunol 2005; 174: 2265-2272.

61. Schaffer MR, Tantry U, Barbul A. Wound fluid inhibits wound fibroblast nitric oxide synthesis. J Surg Res 2004; 122: 43-48.

62. Roy S, Khanna S, Nallu K, Hunt TK, Sen CK. Dermal wound healing is subject to redox control. Mol Ther 2006; 13: 211-220.

63. Li H, Wang C, Guo G, Gao C, Wu Y, Chen Y. The characteristic expression of B7-associated proteins in Langerhans cell sarcoma. Acta Histochem 2012; 114: 733-743.

(i) Cell Death and Disease is an open-access journal published by Nature Publishing Group. This work is licensed under a Creative Commons Attribution 4.0 International Licence. The images or other third party material in this article are included in the article's Creative Commons licence, unless indicated otherwise in the credit line; if the material is not included under the Creative Commons licence, users will need to obtain permission from the licence holder to reproduce the material. To view a copy of this licence, visit http://creativecommons.org/licenses/by/4.0 